\title{
Diferenças florísticas e estruturais entre duas cotas altiduninais da Floresta Ombrófila Densa Submontana Atlântica, do Parque Estadual da Serra do Mar, município de Ubatuba/SP, Brasil
}

\author{
José Ataliba Mantelli Aboin Gomes ${ }^{1}$, Luís Carlos Bernacci ${ }^{1,3}$ \& Carlos Alfredo Joly ${ }^{2}$ \\ ${ }^{I}$ NPD Jardim Botânico, Centro de Recursos Genéticos, Instituto Agronômico - IAC, \\ Av. Theodureto A. Camargo, 1500, Fazenda Santa Elisa, \\ CEP 13075-630, Campinas, SP, Brasil. http://herbario.iac.sp.gov.br \\ ${ }^{2}$ Departamento de Biologia Vegetal, Universidade Estadual de Campinas - UNICAMP, \\ CP 6109, CEP 13083-970, Campinas, SP, Brasil.www.ib.unicamp.br \\ ${ }^{3}$ Autor para correspondência: Luís Carlos Bernacci,e-mail: bernacci@iac.sp.gov.br
}

GOMES, J.A.M.A., BERNACCI, L.C. \& JOLY, C.A. Floristic and structural differences, between two altitudinal quotas, of the Submontane Atlantic Rainforest within the Serra do Mar State Park, municipality of Ubatuba/SP, Brazil. Biota Neotrop. 11(2): http://www.biotaneotropica.org.br/v11n2/en/ abstract?article+bn02611022011

\begin{abstract}
This study presents a comparative analyzes of two areas of Atlantic Rain Forest, in the municipality of Ubatuba (SP), Brazil, and tests the hypothesis that floristic composition and phytosociological structure change along an altitudinal gradient. Two 1-ha plots were installed, respectively, at 190 (PLOT G) and $350 \mathrm{~m}$ (PLOT I) above see level, and within these plots all individuals with $\mathrm{DBH} \geq 4.8 \mathrm{~cm}$ were sampled, measured and identified. In total we found 252 species, belonging to 134 genera and 53 families, diversity H' of 4.425 nats/individual, and 103 species (41\% of total) common to both plots. But, among the 10 top species in Absolute Dominance only two: Cryptocarya mandioccana and Sloanea guianensis were found in both plots. In PLOT G we found 1496 individuals distributed in 152 species, 101 genera and 41 families, with $H^{\prime}=3.961$ nats/individual and 48 exclusive species (32\%). In PLOT I we found 1993 individuals distributed in 203 species, 111 genera, 50 families, with $H^{\prime}=4.339$ nats/individual and 100 exclusive species (49\%). Supporting our hypothesis, the comparative analyzes showed that there are significant differences in density $(\mathrm{p}<0.01, \mathrm{t}=7.10)$, richness $(\mathrm{p}<0.01$, $t=7.76)$ and volume $(p=0.02, t=2.44)$, between the two sampled areas. The pattern here observed shows that the plot installed closer to the middle of the Serra do Mar slope $(350 \mathrm{~m})$ presented a higher number of individuals, higher richness and higher scores of volume, when compared to that closer to the base of the slope (190 m). Keywords: tree diversity, Atlantic Forest, floristic composition, species ricnhness, altitudinal gradient, BIOTA Functional Gradient Project.
\end{abstract}

GOMES, J.A.M.A., BERNACCI, L.C. \& JOLY, C.A. Diferenças florísticas e estruturais entre duas cotas altiduninais da Floresta Ombrófila Densa Submontana Atlântica, do Parque Estadual da Serra do Mar, município de Ubatuba/SP, Brasil. Biota Neotrop. 11(2): http://www.biotaneotropica.org.br/v11n2/pt/ abstract?article+bn02611022011

Resumo: Este estudo apresenta a análise comparativa entre duas áreas da Floresta Atlântica Ombrófila Densa Submontana, em Ubatuba (SP), Brasil e testa a hipótese de que diferenças em altitude podem representar alterações na composição florística e estrutura fitossociológica. As duas parcelas de um hectare $(100 \mathrm{x} 100 \mathrm{~m})$ foram instaladas a 190 (PLOT G) e 350 m (PLOT I) acima do nível do mar, sendo amostrados e identificados todos os indivíduos, exceto lianas, com DAP (Diâmetro à Altura do Peito) $\geq 4.8 \mathrm{~cm}$. No total, foram encontradas 252 espécies, pertencentes a 134 gêneros e 53 famílias, a diversidade H' de 4,425 nats/indivíduos e 103 espécies (41\% do total) em comum entre as duas áreas. Mas, entre as 10 principais espécies em dominância absoluta apenas duas se repetem entre as áreas: Cryptocarya mandioccana e Sloanea guianensis. No PLOT G existem 1.496 indivíduos distribuídos em 152 espécies, 101 gêneros e 41 famílias, com H’ = 3,961 nats/indivíduo e 48 espécies exclusivas à área (32\%). No PLOT I existem 1.993 indivíduos distribuídos em 203 espécies, 111 gêneros, 50 famílias, com H’ = 4,339 nats/indivíduo e 100 espécies exclusivas à área (49\%). Entre as duas parcelas, aos 190 e 350 m, houve diferença significantiva $(\mathrm{gl}=198)$ na densidade $(\mathrm{p}<0,01, \mathrm{t}=7,10)$, riqueza $(\mathrm{p}<0,01, \mathrm{t}=7,76)$ e volume $(\mathrm{p}=0,02, \mathrm{t}=2,44)$. Os resultados indicam que a diversidade específica, estrutura fitossociológica e composição florística diferem entre as duas cotas altitudinais, sendo observados mais indivíduos, maior riqueza e volume na parcela instalada próxima ao meio da encosta (350 m de altitude) do que naquela instalada mais próxima à base da encosta (190 m de altitude).

Palavras-chave: diversidade arbórea, Mata Atlântica, composição florística, riqueza de espécies, gradiente altitudinal, Projeto Temático BIOTA Gradiente Funcional. 


\section{Introdução}

A complexa região fito-geográfica Floresta Ombrófila Densa Atlântica, definida por Veloso et al. (1991), apresenta uma ampla variação de altitude e latitude, além de grandes variações climáticas e edáficas (Torres et al. 1997, Oliveira Filho \& Fontes 2000, Scudeller et al. 2001). Estas variações promovem uma grande heterogeneidade de habitats, possibilitando uma alta diversidade e riqueza de espécies na comunidade vegetal (Mori et al. 1981, Leite \& Klein 1990, Guedes-Bruni \& Lima 1997, Thomas 1998, Joly et al. 1999). Como consequência das variações de habitat em escala local, pode ocorrer diferenças na composição florística e estrutura entre localidades próximas (Leitão Filho1987, Peixoto \& Gentry 1990, Morellato 2000, Ivanauskas et al. 2000).

O Núcleo Picinguaba, parte integrante do Parque Estadual da Serra do Mar, apresenta uma localização ambientalmente estratégica, fazendo a ligação entre o Parque Estadual da Serra do Mar com o Parque Nacional da Serra da Bocaina (80 mil ha), no Estado de São Paulo, e com a Área de Proteção Ambiental (APA) do Cairuçu (30 mil ha), no Estado do Rio de Janeiro, e forma um grande corredor para uma fauna diversificada, infelizmente ameaçada de extinção (Instituto Florestal s/d). Adicionalmente, tem o único ponto do Parque Estadual da Serra do Mar que atinge a orla marítima. A floresta em Picinguaba chega até os costões rochosos e se espalha pela planície litorânea em sete praias. Com uma área de abrangência de 47 mil ha, está totalmente inserido no município de Ubatuba (Instituto Florestal s/d). O conhecimento sobre a composição e estrutura da vegetação na região do litoral norte paulista ainda é muito escasso, podendo-se mencionar os estudos de Silva \& Leitão Filho (1982), em área de encosta; Furlan et al. (1990) e Cesar \& Monteiro (1995), em áreas de restingas; Sanchez et al. (1999), em floresta ripária; Garcia (1995) e Assis (1999), sobre relações do relevo, solo e vegetação; Sanchez (2001), ao longo de gradientes de altitudes.

Diferenças na estrutura e na composição de florestas ao longo de um gradiente de altitude têm sido documentadas em diversos trabalhos ao redor do globo, sendo essas diferenças geralmente atribuídas ou a variações de microclima (Odland \& Birks 1999, Monteiro \& Fisch 2005), ou irradiação solar (Proctor et al. 1988), ou topografia e/ou solo (Rodrigues et al. 1989, Oliveira Filho et al. 1994, Yamakura et al. 1995, Oliveira Filho et al. 1998, Takyu et al. 2002a-b, Martins et al. 2003, Aiba et al. 2004, Carvalho et al. 2005, Cielo Filho et al. 2007), ou à altitude (Lieberman et al. 1985, Sruatek \& Kolbek 1994, Lieberman et al. 1996, Aiba \& Kitayama 1999, Sanchez 2001). Em uma escala local, mecanismos biológicos têm sido reconhecidos como preponderantes para a biodiversidade, enquanto em na macro-escala fatores climáticos ganham importância (Whittaker et al. 2001).

Em florestas tropicias, em montanhas relativamente baixas (até cerca de $1.000 \mathrm{~m}$ ) da Ásia, com a presença frequente de nuvens (altitudes entre $280-870 \mathrm{~m}$, cerca $5^{\circ} \mathrm{N}$ ), a diversidade foi maior na porção intermediária (a cerca de 480-540 m) da encosta (Proctor et al. 1988), enquanto em outra sem a presença frequente de nuvens $\left(200-850 \mathrm{~m}\right.$, cerca $\left.4^{\circ} \mathrm{N}\right)$, foi observado aumento da riqueza, relacionado com o aumento da densidade, em função da altitude (Pendry \& Proctor 1997). Na América Central, em montanha mais alta, a composição e a estrutura da vegetação das florestas variaram com a altitude $\left(100-2600 \mathrm{~m}\right.$, cerca $\left.10^{\circ} \mathrm{N}\right)$, sendo que a áreas de maior riqueza foram aquelas situadas aos 300 e $500 \mathrm{~m}$ de altitude, particularmente na primeira (Lieberman et al. 1996).

No Brasil, para a Mata Atlântica, tem sido evidenciado que tanto padrões florísticos locais como regionais são influenciados pela altitude. Na região sudeste, a altitude foi o principal fator influenciando as diferenças florísticas na Mata Atlântica sensu lato (Oliveira-Filho \& Fontes 2000). Igualmente, no sul de Minas
Gerais (Meireles et al. 2008), foram observadas diferenças florísticas associadas com a altitude. A influência da altitude foi evidenciada entre as florestas semidecíduas (Salis et al. 1995, Torres et al. 1997) e entre as florestas ombrófilas (Scudeller et al. 2001), bem como entre os dois tipos de vegetação (Ivanauskas et al. 2000). Em escala local, na Serra do Japi - SP (Rodrigues et al. 1989), e em Imbé - RJ (Moreno et al. 2003), igualmente, foram observadas diferenças florísticas associadas a diferenças altitudinais.

Em Ubatuba (a cerca de $23^{\circ} \mathrm{S}$ ), no litoral norte de São Paulo, a proximidade entre as Serras do Mar e da Mantiqueira, funciona como barreira tanto das frentes frias, como das convergências úmidas intertropicas, dificultando o avanço desses mecanismos úmidos para o interior do continente, favorecendo as chuvas no litoral, praticamente o ano todo (Barbosa 2006). O presente estudo tem como objetivo avaliar a biodiversidade e se é possível detectar diferenças florísticas e estruturais na cobertura florestal no maçico da Serra do Mar (com altitudes até cerca de $1.200 \mathrm{~m}$ ), entre áreas relativamente próximas entre si. Particularmente, responder às seguintes perguntas: existem e quais são as diferenças na composição florística e estrutura fitossociológica do estrato arbóreo entre um trecho de floresta ombrófila submontana a cerca de $190 \mathrm{~m}$ e outro a cerca de $350 \mathrm{~m}$ de altitude?

\section{Materiais e métodos}

\section{1. Áreas de estudo}

As áreas escolhidas para este estudo estão situadas no Núcleo Picinguaba, do Parque Estadual da Serra do Mar. A vegetação pode ser classificada como Floresta Ombrófila Densa Submontana (Veloso et al. 1991), sendo que o clima regional, de acordo com o sistema de Köppen (1948), é Af (tropical chuvoso), sem estação seca e com uma precipitação média anual de 2.600 mm (Sanchez et al. 1999). Nos meses mais secos, junho a agosto, a precipitação média mensal nunca é inferior a $60 \mathrm{~mm}$ e no mês mais chuvoso, janeiro, chega a atingir $370 \mathrm{~mm}$, sendo que a umidade relativa nunca é inferior a $85 \%$ (Sanchez et al. 1999). As duas áreas, PLOT G e PLOT I (Joly et al. 2011), eram distantes aproximadamente $700 \mathrm{~m}$ entre si, sendo distribuídas em uma mesma encosta, às quais se chega através de uma mesma trilha (que é praticamente o único acesso a elas, e utilizada desde o passado distante). O solo (Martins 2010), nos locais que incluem as áreas de estudo, apresenta textura franco-argilo-arenosa, sendo que a maior reserva nutricional encontra-se nos primeiros centímetros (0-5 cm), com $4.600 \mathrm{ppm}\left(\mathrm{mg}^{\mathrm{kg}} \mathrm{kg}^{-1}\right)$ de nitrogênio $(\mathrm{N}$, média de 2-2,5 g. $\mathrm{kg}^{-1}$ até $1 \mathrm{~m}$ de profundidade), mas a fertilidade é considerada baixa (embora o solo seja significativamente mais fértil que em locais próximos, em outras altitudes) e elevados os níveis de $\mathrm{Al}$ (significativamente mais baixos que em menores altitudes).

$\mathrm{Na}$ área considerada como aos $190 \mathrm{~m}$ de altitude (PLOT G $23^{\circ} 22^{\prime} 26^{\prime}$ ' S e $45^{\circ} 04^{\prime} 51^{\prime \prime} \mathrm{W}$ ), a altitude variou de 176 a $198 \mathrm{~m}$ (média de $188 \mathrm{~m}$, havendo uma diferença de $22 \mathrm{~m}$ entre a menor e maior altitude), e naquela considerada aos $350 \mathrm{~m}$ (média das altitudes - PLOT I - $23^{\circ} 22^{\prime} 01^{\prime}$ ' S e $45^{\circ} 05^{\prime} 01^{\prime}$ ' W) a amplitude de variação da altitude foi maior $(49 \mathrm{~m})$ indo de 325 a $374 \mathrm{~m}$.

\section{Análises florística e fitossociológica}

A marcação, medição e coleta de material botânico seguiram o protocolo do Projeto Temático Biota Gradiente Funcional (Joly et al. 2011), sendo amostramos todos os indivíduos, excluindo lianas, contidos em cada parcela de um hectare $(100 \times 100 \mathrm{~m})$, utilizando o critério de inclusão DAP (diâmetro à altura do peito) $\geq 4,8 \mathrm{~cm}$.

Para cada espécie amostrada ao menos um material-testemunho foi incorporado ao Herbário IAC (http://herbario.iac.sp.gov.br/), sendo 
as duplicatas distribuídas para os herbários das outras instituições participantes do projeto temático, UEC (UNICAMP, Campinas - SP) e HRCB (UNESP, Rio Claro - SP), para o herbário SPSF (Instituto Florestal, São Paulo - SP), da instituição responsável pela unidade de conservação, e para os herbários dos especialistas que colaboraram com as identificações.

Para a delimitação das famílias utilizou-se a classificação proposta em APG II (Angiosperm... 2003). A identificação das espécies foi feita através de consultas a várias obras de referência, como a Flora Fanerogâmica do Estado de São Paulo (Wanderley et al. 2002, 2003, 2005, 2007, 2009) e por comparação com amostras do acervo dos herbários das instituições participantes. Os nomes das espécies foram atualizados de acordo com revisões taxonômicas recentes e consulta aos bancos de dados do Tropicos (http:// www.tropicos.org/), World Checklist of Selected Plant Families (http://apps.kew.org/wcsp/qsearch.do) e Lista de espécies da flora do Brasil (http://floradobrasil.jbrj.gov.br/2010/). Em muitos casos, contou-se com a colaboração de especialistas participantes do projeto ou de outras instituições, para a confirmação ou identificação. O risco de ameaça de extinção de cada uma das espécies foi verificado, de acordo com as informações da IUCN (International... 2006), Biodiversitas (2008) e SMA (Brasil 2008). As espécies não identificadas receberam numeração sequencial, considerando todas as parcelas estudadas através do projeto.

Os parâmetros fitossociológicos analisados foram densidade, frequiência absoluta, dominância absoluta e importância (VI) para cada espécie (Mueller-Dombois \& Ellenberg 1974), e o índice de diversidade H' de Shannon (Magurran 1988). Os cálculos foram realizados com o auxílio do software FITOPAC (Shepherd 1995). Para verificar as diferenças entre os valores médios de densidade absoluta, de área basal, de volume e de riqueza entre as parcelas foi feita uma comparação através do teste t de Student (Zar 1999), sendo que o nível de relevância considerado foi $95 \%$. Os testes foram feitos através do software Bioestat 2.0 (Ayres et al. 2000).

\section{Resultados}

No total, amostramos 3.489 indivíduos vivos, sendo Rubiaceae a família mais abundante, com 951 indivíduos amostrados (27\% do total), seguida por Myrtaceae, com 503 indivíduos, e Arecaceae, 478 indivíduos (14\% do total, cada). As outras famílias somaram, no máximo, $5 \%$ dos indivíduos, cada, sendo que seis delas (Lacistemataceae, Malpighiaceae, Opiliaceae, Phytolaccaceae, Picramniaceae e Rosaceae) foram representadas por apenas um indivíduo cada.

Considerando as duas parcelas, amostramos 251 espécies, pertencentes a 134 gêneros e 53 famílias (Tabela 1). Deste total, determinamos 22 espécies apenas ao nível de gênero (quatro das quais em fase de descrição ou validação de combinação), duas apenas ao de família (Humiriaceae sp. e Sapotaceae sp.2), e uma espécie permaneceu desconhecida (Indeterminada sp.2). As cinco famílias com maior riqueza, considerando as duas parcelas em conjunto, foram Myrtaceae (58 espécies), Rubiaceae (24), Fabaceae (23) Lauraceae (15) e Sapotaceae (11), que somadas perfazem 52\% do total de espécies. No outro extremo, 21 famílias foram representadas por uma única espécie. Os gêneros mais ricos foram Eugenia, 28 espécies; Ocotea, com oito espécies; Marliera, Miconia, Myrcia e Psychotria, sete; Calyptranthes e Inga, seis; e Mollinedia, com cinco espécies. Reconhecemos 103 espécies (41\%) em comum entre as duas localidades.

Aos 190 m (Tabela 1), amostramos 1.496 indivíduos vivos, observando que as famílias mais abundantes, foram Rubiaceae, com 433 indivíduos amostrados (29\% dos indivíduos), Myrtaceae, com 225 indivíduos (15\%), Arecaceae, 177 indivíduos (12\%), Monimiaceae, 98 (7\% do total de indivíduos) e Lauraceae 68 indivíduos (5\% do total de indivíduos). Juntas, estas cinco famílias representaram $67 \%$ do total de indivíduos amostrados. No outro extremo, seis famílias (Bignoniaceae, Lacistemataceae, Lecythidaceae, Phyllanthaceae, Rosaceae e Salicaceae) foram representadas por um único indivíduo cada.

Encontramos 152 espécies (das quais duas identificadas apenas até o nível de famílias), 101 gêneros e 41 famílias, na parcela a cerca de $190 \mathrm{~m}$ de altitude (Tabela 1). A família mais rica foi Myrtaceae, com 30 espécies (20\% da riqueza total); destas, oito espécies foram amostradas somente nesta cota altitudinal. A segunda família com maior riqueza foi Fabaceae, com 18 espécies (12\% da riqueza), sendo oito exclusivas; seguida por Rubiaceae, com 15 espécies (10\%), sendo cinco exclusivas; Lauraceae e Sapotaceae, com oito espécies cada (5\% da riqueza total, cada), com cinco e duas espécies exclusivas, respectivamente. Quinze famílias apresentaram uma única espécie, aos 190 m, sendo que três delas (Lacistemaceae, Ochnaceae e Rosaceae) foram amostradas somente nesta cota altitudinal.

Observamos que as dez espécies mais abundantes, aos $190 \mathrm{~m}$, somadas, perfizeram $48 \%$ do total dos indivíduos amostrados. Rudgea jasminoides, com 234 indivíduos (16\% dos indivíduos) foi a espécie mais abundante, seguida por Euterpe edulis, com 116 indivíduos (8\%), e Mollinedia schottiana, 64 indivíduos; Coussarea accendens, 60, e Eugenia prasina, 57 indivíduos, correspondendo a 4\% dos indivíduos cada. Aos 190 m, a espécie mais frequente foi Rudgea jasmineoides (que ocorreu em 83\% das subparcelas). Obtivemos 3,959 nats/indivíduo no índice de Shannon (H'), para as espécies, e 47,705 m².ha-1, para a área basal, aos $190 \mathrm{~m}$. Encontramos, nesta parcela, 74 árvores mortas, que juntas atingiram uma área basal de $3,7 \mathrm{~m}^{2} \cdot \mathrm{ha}^{-1}$. As árvores vivas com DAP igual ou maior a $10 \mathrm{~cm}$ somaram 718 indivíduos (48\% do total de vivos) e 129 espécies (85\% do total).

Aos 350 m, amostramos 1.993 indivíduos vivos, sendo que a família Rubiaceae, foi a mais abundante, com 518 indivíduos (26\% dos indivíduos), seguida por Arecaceae, com 301 indivíduos (15\%), Myrtaceae, com 278 (14\%), Sapotaceae, com 88 (4\%) e Monnimiaceae, com 68 indivíduos (3\% dos indivíduos). No outro extremo, sete famílias Asteraceae, Combretaceae, Lamiaceae, Malpighiaceae, Opiliaceae, Phytolaccaceae e Picramniaceae, foram representadas por um único indivíduo cada.

Idenficamos um total de 203 espécies (uma não identificada ao nível de família) e 111 gêneros, distribuídos em 50 famílias, aos 350 m. A família mais rica foi Myrtaceae, com 50 espécies (25\% da riqueza), das quais 28 exclusivas desta faixa altitudinal. Seguiram-na Rubiaceae, com 19 espécies ( $9 \%$ da riqueza), sendo nove exclusivas; Fabaceae, com 15 espécies ( $7 \%$ da riqueza), cinco delas exclusivas; Lauraceae, com dez espécies (5\%), sete exclusivas; e Sapotaceae, com nove espécies (4\% da riqueza), sendo três delas amostradas somente nesta cota altitudinal. Vinte e quatro famílias apresentaram uma única espécie, aos 350 m, sendo que doze delas, Burseraceae, Caricaceae, Cunoniaceae, Erythroxylaceae, Magnoliaceae, Malpighiaceae, Memecylaceae, Opiliaceae, Phytolaccaceae, Picramniaceae, Proteaceae e Vochysiaceae, foram amostradas exclusivamente nesta faixa de altitude.

A espécie mais freqüente, aos $350 \mathrm{~m}$, foi Euterpe edulis (ocorrendo em 63\% das subparcelas). Observamos que as dez espécies mais abundantes somadas perfizeram $43 \%$ do total dos indivíduos amostrados, sendo a mais abundante Bathysa mendoncaei, com 218 indivíduos (11\% dos indivíduos), seguida por Euterpe edulis, com 139 indivíduos (7\%), Syagrus pseudococos, 99 indivíduos (5\%), Coussarea meridionalis, 81 (4\%) e Eriotheca pentaphylla e Faramea pachyantha, com 62 indivíduos cada (3\% dos indivíduos). 
Tabela 1. Espécies arbóreas e seus parâmetros fitossociológicos no PLOT G (190 m) e PLOT I (350 m) no Parque Estadual da Serra do Mar, Núcleo Picinguaba, Ubatuba/SP, Brasil. IAC número de registro no Herbário do Instituto Agronômico. s/n sem amostra incluída na coleção; N número de indivíduos amostrados; FrA freqüência absoluta; DoA dominância absoluta; - ausência.

Table 1. Tree species and their phytosociological parameters in PLOT G (190 m) and PLOT I (350 m), Serra do Mar State Park, Nucleo Picinguaba, Ubatuba/ SP, Brazil. IAC registration number in the Herbarium of the Agronomy Institute o Campinas/IAC. s/n sample not included in the collection, $\mathrm{N}$ number of individuals sampled; FrA absolute frequency; DoA absolute dominance, - absence.

\begin{tabular}{|c|c|c|c|c|c|c|c|c|}
\hline \multirow[t]{2}{*}{ Família } & \multirow[t]{2}{*}{ Espécies } & \multirow[t]{2}{*}{ IAC } & \multicolumn{3}{|c|}{ PLOT I } & \multicolumn{3}{|c|}{ PLOT G } \\
\hline & & & $\mathbf{N}$ & FrA & DoA & $\mathbf{N}$ & FrA & DoA \\
\hline \multirow[t]{3}{*}{ Annonaceae } & Annona cacans Warm. & 48941 & 1 & 1 & 0,91 & 1 & 1 & 1,14 \\
\hline & Guatteria australis A.St.-Hil. & 48947 & 7 & 7 & 2,73 & 5 & 5 & 0,79 \\
\hline & Rollinia sericea (R.E.Fr.) R.E.Fr. & 48948 & 3 & 3 & 1,02 & 8 & 7 & 3,72 \\
\hline Apocynaceae & Malouetia arborea (Vell.) Miers & 48949 & 13 & 13 & 8,37 & 7 & 6 & 1,77 \\
\hline \multirow[t]{2}{*}{ Aquifoliaceae } & Ilex sp. & 48957 & 2 & 2 & 0,11 & 2 & 2 & 0,47 \\
\hline & Ilex theezans Mart. ex Reissek & 50289 & 7 & 7 & 12,22 & - & - & - \\
\hline \multirow[t]{3}{*}{ Araliaceae } & Dendropanax cuneatus (DC.) Decne. \& Planch. & 48976 & 3 & 3 & 0,62 & 1 & 1 & 0,23 \\
\hline & Schefflera angustissima (Marchal) Frodin & 50290 & 6 & 6 & 1,38 & - & - & - \\
\hline & Schefflera calva (Cham.) Frodin \& Fiaschi & 48950 & 10 & 8 & 1,24 & 6 & 6 & 0,75 \\
\hline \multirow[t]{5}{*}{ Arecaceae } & Astrocaryum aculeatissimum (Schott) Burret & $\mathrm{s} / \mathrm{n}$ & 56 & 40 & 4,75 & 9 & 8 & 0,81 \\
\hline & Attalea dubia (Mart.) Burret & $\mathrm{s} / \mathrm{n}$ & 5 & 5 & 3,98 & - & - & - \\
\hline & Bactris setosa Mart. & 50521 & 2 & 2 & 0,05 & - & - & - \\
\hline & Euterpe edulis Mart. & 49271 & 139 & 63 & 7,71 & 116 & 66 & 7,9 \\
\hline & Syagrus pseudococos (Raddi) Glassman & 49191 & 99 & 62 & 16,13 & 52 & 36 & 8,8 \\
\hline \multirow[t]{2}{*}{ Asteraceae } & Vernonia discolor (Spreng.) Less. & 48991 & - & - & - & 1 & 1 & 0,13 \\
\hline & Vernonia puberula Less. & 48951 & 1 & 1 & 0,5 & 1 & 1 & 0,59 \\
\hline \multirow[t]{2}{*}{ Bignoniaceae } & Jacaranda puberula Cham. & 50292 & 1 & 1 & 0,05 & - & - & - \\
\hline & Tabebuia serratifolia (Vahl) G.Nicholson & 48952 & 11 & 11 & 1,7 & 1 & 1 & 0,43 \\
\hline \multirow[t]{2}{*}{ Boraginaceae } & Cordia silvestris Fresen. & 50293 & 3 & 3 & 2,3 & - & - & - \\
\hline & Cordia taguahyensis Vell. & 48953 & 25 & 23 & 3,24 & 19 & 16 & 3,95 \\
\hline Burseraceae & Protium kleinii Cuatrec. & 50294 & 3 & 2 & 3,58 & - & - & - \\
\hline Cardiopteridaceae & Citronella paniculata (Mart.) R.A.Howard & 48954 & 7 & 5 & 3,23 & 18 & 16 & 4,81 \\
\hline Caricaceae & Jacaratia heptaphylla (Vell.) A. DC. & 48954 & 2 & 2 & 0,24 & - & - & - \\
\hline \multirow[t]{5}{*}{ Celastraceae } & Maytenus sp.1 & 48977 & - & - & - & 2 & 2 & 0,94 \\
\hline & $\begin{array}{l}\text { Maytenus sp.2 (espécie inédita) [=M. ubatubensis Carv.- } \\
\text { Okano] }\end{array}$ & 48956 & - & - & - & 3 & 2 & 0,11 \\
\hline & Maytenus sp.5 & 50295 & 1 & 1 & 0,56 & - & - & - \\
\hline & Peritassa flaviflora A.C.Sm. & 50296 & 1 & 1 & 1,61 & - & - & - \\
\hline & Salacia grandifolia (Mart. ex Schult.) G.Don & 48959 & - & - & - & 4 & 4 & 0,16 \\
\hline \multirow[t]{6}{*}{ Chrysobalanaceae } & Couepia venosa Prance & 48961 & 2 & 2 & 0,1 & 9 & 9 & 1,62 \\
\hline & Hirtella hebeclada Moric. ex DC. & 48962 & 22 & 20 & 8,26 & 2 & 2 & 0,68 \\
\hline & Licania hoehnei Pilg. & 48963 & 16 & 13 & 8,01 & 9 & 8 & 14,3 \\
\hline & Licania kunthiana Hook.f. & 50299 & 4 & 4 & 0,25 & - & - & - \\
\hline & $\begin{array}{l}\text { Licania octandra (Hoffmanns. ex Roem. \& Schult.) } \\
\text { Kuntze }\end{array}$ & 50301 & 10 & 10 & 0,48 & - & - & - \\
\hline & Parinari excelsa Sabine & 50302 & 5 & 5 & 0,82 & - & - & - \\
\hline \multirow[t]{2}{*}{ Clusiaceae } & Clusia lanceolata Cambess. & 48969 & - & - & - & 2 & 2 & 0,1 \\
\hline & Garcinia gardneriana (Planch. \& Triana) Zappi & 48970 & 37 & 27 & 3,92 & 27 & 20 & 2,93 \\
\hline Combretaceae & Terminalia januarensis DC. & 48972 & 1 & 1 & 0,46 & 5 & 5 & 10,2 \\
\hline Cunoniaceae & Lamanonia ternata Vell. & 50304 & 2 & 2 & 0,65 & - & - & - \\
\hline \multirow[t]{3}{*}{ Cyatheaceae } & Alsophila sternbergii (Sternb.) D.S.Conant & 48973 & - & - & - & 3 & 2 & 0,28 \\
\hline & Cyathea atrovirens (Langsd. \& Fisch.) Domin & 50284 & 17 & 16 & 0,39 & - & - & - \\
\hline & Cyathea phalerata Mart. & 48975 & - & - & - & 4 & 4 & 0,27 \\
\hline \multirow[t]{2}{*}{ Elaeocarpaceae } & Sloanea guianensis (Aubl.) Benth. & 48968 & 24 & 18 & 24,4 & 22 & 20 & 74,1 \\
\hline & Sloanea monosperma Vell. & 49245 & 3 & 3 & 0,1 & - & - & - \\
\hline Erythroxylaceae & Erythroxylum pulchrum A.St.-Hil. & 50305 & 2 & 1 & 1,03 & - & - & - \\
\hline Euphorbiaceae & Alchornea triplinervia (Spreng.) Müll.Arg. & 48965 & - & - & - & 4 & 4 & 7,53 \\
\hline
\end{tabular}


Tabela 1. Continuação...

\begin{tabular}{|c|c|c|c|c|c|c|c|c|}
\hline \multirow[t]{2}{*}{ Família } & \multirow[t]{2}{*}{ Espécies } & \multirow[t]{2}{*}{ IAC } & \multicolumn{3}{|c|}{ PLOT I } & \multicolumn{3}{|c|}{ PLOT G } \\
\hline & & & $\mathbf{N}$ & FrA & DoA & $\mathbf{N}$ & FrA & DoA \\
\hline & Mabea piriri Aubl. & 48966 & 5 & 5 & 2,12 & 1 & 1 & 0,02 \\
\hline & Pausandra morisiana (Casar.) Radlk. & 49780 & 7 & 7 & 1,2 & - & - & - \\
\hline & Pera glabrata (Schott) Poepp. ex Baill. & 50306 & 7 & 7 & 2,71 & - & - & - \\
\hline & Sapium glandulosum (L.) Morong & 48967 & 1 & 1 & 1,62 & 1 & 1 & 0,6 \\
\hline & Tetrorchidium rubrivenium Poepp. & 49117 & 2 & 2 & 0,06 & - & - & - \\
\hline \multirow[t]{5}{*}{ Fabaceae-Caesalpinoideae } & Copaifera langsdorffii Desf. & 49313 & 2 & 2 & 1,16 & 3 & 3 & 2,2 \\
\hline & Copaifera trapezifolia Hayne & 50309 & 4 & 4 & 3,58 & - & - & - \\
\hline & $\begin{array}{l}\text { Hymenaea courbaril var. altissima (Ducke) Y.T. Lee \& } \\
\text { Langenh. }\end{array}$ & 50309 & 4 & 4 & 19,93 & - & - & - \\
\hline & Tachigali denudata (Vogel) Oliveira-Filho & 49314 & 2 & 2 & 2,32 & 3 & 2 & 0,12 \\
\hline & Tachigali multijuga Benth. & 49312 & - & - & - & 2 & 2 & 0,48 \\
\hline \multirow[t]{9}{*}{ Fabaceae-Faboideae } & Andira anthelmia (Vell.) J.F.Macbr. & 50307 & 1 & 1 & 0,27 & - & - & - \\
\hline & Andira fraxinifolia Benth. & 49307 & 1 & 1 & 9,74 & 1 & 1 & 0,44 \\
\hline & Dahlstedtia pinnata (Benth.) Malme & 49322 & 15 & 11 & 1,08 & 8 & 7 & 0,3 \\
\hline & $\begin{array}{l}\text { Lonchocarpus cultratus (Vell.) A.M.G.Azevedo \& } \\
\text { H.C.Lima }\end{array}$ & 49319 & - & - & - & 1 & 1 & 0,1 \\
\hline & Myrocarpus frondosus Allemão & 49317 & - & - & - & 3 & 3 & 6,41 \\
\hline & Ormosia arborea (Vell.) Harms & 49316 & 4 & 4 & 0,25 & 1 & 1 & 0,05 \\
\hline & Pterocarpus rohrii Vahl & 49315 & - & - & - & 4 & 4 & 5,74 \\
\hline & Swartzia langsdorffii Raddi & 49306 & 5 & 5 & 1,11 & 2 & 2 & 2,98 \\
\hline & Zollernia ilicifolia (Brongn.) Vogel & 49308 & - & - & - & 3 & 3 & 2,16 \\
\hline \multirow[t]{9}{*}{ Fabaceae-Mimosoideae } & Inga capitata Desv. & 50313 & 10 & 10 & 3,59 & - & - & - \\
\hline & Inga edulis Mart. & 49311 & 1 & 1 & 0,16 & 1 & 1 & 0,16 \\
\hline & Inga grazielae (Vinha) T.D.Penn. & 49310 & - & - & - & 3 & 3 & 0,06 \\
\hline & Inga marginata Willd. & 49321 & - & - & - & 1 & 1 & 0,06 \\
\hline & Inga schinifolia Benth. & 49319 & 2 & 2 & 0,09 & 1 & 1 & 0,13 \\
\hline & Inga striata Benth. & 49320 & 2 & 2 & 0,11 & 1 & 1 & 0,11 \\
\hline & Piptadenia paniculata Benth. & 49330 & - & - & - & 1 & 1 & 1,77 \\
\hline & Pseudopiptadenia leptostachya (Benth.) Rauschert & 49309 & 6 & 6 & 1,36 & 12 & 11 & 4,23 \\
\hline & $\begin{array}{l}\text { Pseudopiptadenia warmingii (Benth.) G.P.Lewis \& } \\
\text { M.P.Lima }\end{array}$ & 50314 & 2 & 2 & 16,51 & - & - & - \\
\hline Família indeterminada & indeterminada sp.02 & incluir & 2 & 2 & 0,36 & - & - & - \\
\hline \multirow[t]{2}{*}{ Humiriaceae } & Humiriaceae sp. & 48960 & - & - & - & 4 & 4 & 1,24 \\
\hline & Vantanea sp. & 50315 & 9 & 9 & 1,95 & - & - & - \\
\hline Lacistemataceae & Lacistema lucidum Schnizl. & 48978 & - & - & - & 1 & 1 & 0,19 \\
\hline \multirow[t]{2}{*}{ Lamiaceae } & Aegiphila integrifolia (Jacq.) B.D.Jacks. & 49012 & 1 & 1 & 0,25 & 1 & 1 & 0,47 \\
\hline & Vitex cymosa Bertero ex Spreng. & 49013 & - & - & - & 3 & 3 & 28,2 \\
\hline \multirow[t]{14}{*}{ Lauraceae } & Aniba firmula (Nees \& Mart.) Mez & 50317 & 1 & 1 & 0,23 & - & - & - \\
\hline & Aniba viridis $\mathrm{Mez}$ & 50318 & 1 & 1 & 0,25 & - & - & - \\
\hline & Cryptocarya mandioccana Meisn. & 48980 & 26 & 21 & 34,25 & 32 & 26 & 52,5 \\
\hline & Cryptocarya saligna $\mathrm{Mez}$ & 48981 & 3 & 3 & 0,41 & 4 & 4 & 0,78 \\
\hline & Licaria armeniaca (Nees) Kosterm. & 48982 & - & - & - & 1 & 1 & 0,22 \\
\hline & Nectandra nitidula Nees & 48983 & - & - & - & 1 & 1 & 0,38 \\
\hline & Ocotea beyrichii (Nees) Mez & 48984 & - & - & - & 1 & 1 & 0,29 \\
\hline & Ocotea brachybotra (Meisn.) Mez & 48985 & - & - & - & 1 & 1 & 0,79 \\
\hline & Ocotea dispersa (Nees) Mez & 48986 & 9 & 9 & 0,46 & 27 & 26 & 8,63 \\
\hline & Ocotea elegans $\mathrm{Mez}$ & 50323 & 1 & 1 & 0,24 & - & - & - \\
\hline & Ocotea insignis $\mathrm{Mez}$ & 50322 & 1 & 1 & 0,11 & - & - & - \\
\hline & Ocotea odorifera (Vell.) Rohwer & 50324 & 3 & 2 & 0,39 & - & - & - \\
\hline & Ocotea tabacifolia (Meisn.) Rohwer & 48987 & - & - & - & 1 & 1 & 0,21 \\
\hline & Ocotea venulosa (Nees) Baitello & 50523 & 8 & 8 & 1,36 & - & - & - \\
\hline
\end{tabular}


Tabela 1. Continuação...

\begin{tabular}{|c|c|c|c|c|c|c|c|c|}
\hline \multirow[t]{2}{*}{ Família } & \multirow[t]{2}{*}{ Espécies } & \multirow[t]{2}{*}{ IAC } & \multicolumn{3}{|c|}{ PLOT I } & \multicolumn{3}{|c|}{ PLOT G } \\
\hline & & & $\mathbf{N}$ & FrA & DoA & $\mathbf{N}$ & FrA & DoA \\
\hline & $\begin{array}{l}\text { Rhodostemonodaphne macrocalyx (Meisn.) Rohwer ex } \\
\text { Madriñán }\end{array}$ & 50325 & 1 & 1 & 0,15 & - & - & - \\
\hline Lecythidaceae & Cariniana estrellensis (Raddi) Kuntze & 48979 & 4 & 4 & 3,76 & 1 & 1 & 0,02 \\
\hline Magnoliaceae & Magnolia ovata (A.St.-Hil.) Spreng. & 50333 & 3 & 3 & 0,37 & - & - & - \\
\hline Malpighiaceae & Byrsonima ligustrifolia A.Juss. & 50334 & 1 & 1 & 0,03 & - & - & - \\
\hline \multirow[t]{2}{*}{ Malvaceae } & Eriotheca pentaphylla (Vell.) A.Robyns & 49009 & 62 & 44 & 22,45 & 19 & 14 & 2,75 \\
\hline & Quararibea turbinata (Sw.) Poir. & 48988 & - & - & - & 6 & 6 & 0,15 \\
\hline \multirow[t]{8}{*}{ Melastomataceae } & Meriania calyptrata (Naudin) Triana & 48989 & - & - & - & 8 & 8 & 0,63 \\
\hline & Miconia cabussu Hoehne & 50327 & 2 & 2 & 0,71 & - & - & - \\
\hline & Miconia cinnamomifolia (DC.) Naudin & 50328 & 3 & 3 & 10,49 & - & - & - \\
\hline & Miconia dodecandra Cogn. & 50329 & 1 & 1 & 0,2 & - & - & - \\
\hline & Miconia petropolitana Cogn. & 50330 & 14 & 13 & 0,64 & - & - & - \\
\hline & Miconia sp.1 (espécie inédita) & 48990 & - & - & - & 1 & 1 & 0,09 \\
\hline & Miconia tristis Spring ex Mart. & 50331 & 1 & 1 & 0,05 & 1 & 1 & 0,21 \\
\hline & Miconia valtheri Naudin & 50332 & 1 & 1 & 0,07 & - & - & - \\
\hline \multirow[t]{5}{*}{ Meliaceae } & Cabralea canjerana (Vell.) Mart. & 48992 & 3 & 3 & 1,16 & 3 & 3 & 3,29 \\
\hline & Cedrela odorata $\mathrm{L}$. & 48993 & - & - & - & 1 & 1 & 0,34 \\
\hline & Guarea macrophylla subsp. tuberculata (Vell.) T.D.Penn. & 48994 & - & - & - & 5 & 5 & 2,15 \\
\hline & Trichilia lepidota Mart. & 50336 & 1 & 1 & 0,08 & - & - & - \\
\hline & Trichilia silvatica C.DC. & 50337 & 16 & 14 & 4,6 & 4 & 4 & 2,2 \\
\hline Memecylaceae & Mouriri chamissoana Cogn. & 50338 & 4 & 4 & 0,12 & - & - & - \\
\hline \multirow[t]{6}{*}{ Monnimiaceae } & Macrotorus utriculatus Perkins & 50339 & 7 & 7 & 0,44 & - & - & - \\
\hline & Mollinedia argyrogyna Perkins & 50340 & 17 & 16 & 6,65 & - & - & - \\
\hline & Mollinedia boracensis Peixoto & 48995 & 3 & 3 & 0,47 & 18 & 15 & 2,1 \\
\hline & Mollinedia schottiana (Spreng.) Perkins & 49011 & 9 & 8 & 0,44 & 64 & 45 & 4,13 \\
\hline & Mollinedia ovata Ruiz \& Pav. & 49010 & 15 & 14 & 0,76 & 16 & 16 & 1,93 \\
\hline & Mollinedia triflora (Spreng.) Tul. & 50342 & 17 & 15 & 1,39 & - & - & - \\
\hline \multirow[t]{6}{*}{ Moraceae } & Brosimum guianense (Aubl.) Huber & 48996 & 12 & 10 & 2,69 & 1 & 1 & 0,07 \\
\hline & Brosimum lactescens (S.Moore) C.C.Berg & 49800 & 2 & 2 & 0,39 & - & - & - \\
\hline & Ficus hirsuta Schott & Incluir & - & - & - & 1 & 1 & 0,06 \\
\hline & Ficus insipida Willd. & 49156 & 5 & 5 & 11,57 & - & - & - \\
\hline & $\begin{array}{l}\text { Sorocea bonplandii (Baill.) W.C.Burger, Lanj. \& Wess. } \\
\text { Boer }\end{array}$ & 48997 & 1 & 1 & 0,03 & 1 & 1 & 0,59 \\
\hline & Sorocea hilarii Gaudich. & 48998 & 24 & 20 & 3,02 & 6 & 6 & 0,99 \\
\hline \multirow[t]{2}{*}{ Myristicaceae } & Virola bicuhyba (Schott ex Spreng.) Warb. & 49001 & 5 & 5 & 2,6 & 10 & 10 & 20,9 \\
\hline & Virola gardneri (A.DC.) Warb. & 50353 & 25 & 21 & 28,39 & 1 & 1 & 0,26 \\
\hline \multirow[t]{3}{*}{ Myrsinaceae } & Ardisia martiana Miq. & 48999 & 12 & 12 & 0,51 & 42 & 35 & 1,42 \\
\hline & Rapanea gardneriana (A.DC.) Mez & 50356 & 1 & 1 & 0,18 & - & - & - \\
\hline & Rapanea hermogenesii Jung-Mend. \& Bernacci & 49000 & 4 & 4 & 0,57 & 4 & 4 & 0,84 \\
\hline \multirow[t]{11}{*}{ Myrtaceae } & Calyptranthes grandifolia O.Berg & 50357 & 12 & 12 & 2,68 & - & - & - \\
\hline & Calyptranthes lucida Mart. ex DC. & 49046 & 23 & 21 & 9,62 & 14 & 13 & 5,83 \\
\hline & Calyptranthes rufa O.Berg & 49047 & - & - & - & 4 & 4 & 0,24 \\
\hline & $\begin{array}{l}\text { Calyptranthes sp. } 1 \text { (espécie inédita) [=C. ubatubana } \\
\text { Sobral \& Rochelle] }\end{array}$ & 50358 & 5 & 5 & 4,13 & - & - & - \\
\hline & Calyptranthes sp. 2 & Sobral & 1 & 1 & 0,68 & - & - & - \\
\hline & Calyptranthes strigipes O.Berg & 49048 & 21 & 20 & 10,99 & 6 & 6 & 0,97 \\
\hline & Campomanesia guaviroba (DC.) Kiaersk. & 49044 & 1 & 1 & 0,09 & 1 & 1 & 1,02 \\
\hline & Campomanesia laurifolia Gardner & 49045 & 1 & 1 & 0,17 & 1 & 1 & 0,35 \\
\hline & Eugenia batingabranca Sobral & 49866 & 12 & 12 & 0,88 & - & - & - \\
\hline & Eugenia brasiliensis Lam. & 50361 & 7 & 7 & 1,65 & - & - & - \\
\hline & Eugenia capitulifera O.Berg & 50362 & 1 & 1 & 0,15 & - & - & - \\
\hline
\end{tabular}


Tabela 1. Continuação...

\begin{tabular}{|c|c|c|c|c|c|c|c|c|}
\hline \multirow[t]{2}{*}{ Família } & \multirow[t]{2}{*}{ Espécies } & \multirow[t]{2}{*}{ IAC } & \multicolumn{3}{|c|}{ PLOT I } & \multicolumn{3}{|c|}{ PLOT G } \\
\hline & & & $\mathbf{N}$ & FrA & DoA & $\mathbf{N}$ & FrA & DoA \\
\hline & Eugenia cerasiflora Miq. & 49049 & 1 & 1 & 0,11 & 1 & 1 & 1 \\
\hline & Eugenia flamingensis O.Berg & 49060 & - & - & - & 2 & 2 & 0,23 \\
\hline & Eugenia cuprea (O.Berg) Mattos & 49050 & 6 & 6 & 0,23 & 5 & 5 & 0,36 \\
\hline & Eugenia excelsa O.Berg & 49051 & 10 & 10 & 2,34 & 1 & 1 & 0,72 \\
\hline & Eugenia fusca O.Berg & 49052 & 1 & 1 & 0,51 & 3 & 3 & 1,02 \\
\hline & Eugenia involucrata DC. & 50365 & 3 & 3 & 0,15 & - & - & - \\
\hline & Eugenia melanogyna (D.Legrand) Sobral & 50366 & 3 & 3 & 0,63 & - & - & - \\
\hline & Eugenia monosperma Vell. & 49053 & 2 & 2 & 0,2 & 13 & 10 & 1,7 \\
\hline & Eugenia mosenii (Kausel) Sobral & 50367 & 5 & 5 & 0,39 & - & - & - \\
\hline & Eugenia multicostata D.Legrand & 50368 & 1 & 1 & 0,58 & - & - & - \\
\hline & Eugenia neoaustralis Sobral & 49054 & 5 & 4 & 1,01 & 2 & 2 & 0,47 \\
\hline & Eugenia oblongata O.Berg & 49055 & 10 & 9 & 1,3 & 26 & 21 & 6,47 \\
\hline & Eugenia prasina O.Berg & 49056 & 23 & 20 & 1,32 & 57 & 43 & 3,35 \\
\hline & Eugenia pruniformis Cambess. & 49057 & - & - & - & 1 & 1 & 0,26 \\
\hline & Eugenia sp.02 & Sobral & 2 & 2 & 0,11 & - & - & - \\
\hline & Eugenia sp.03 & Sobral & 1 & 1 & 0,02 & - & - & - \\
\hline & Eugenia sp.04 & Sobral & 1 & 1 & 0,02 & - & - & - \\
\hline & Eugenia sp.05 & Sobral & 1 & 1 & 0,16 & - & - & - \\
\hline & Eugenia sp.06 & Sobral & 2 & 2 & 0,06 & - & - & - \\
\hline & Eugenia sp.07 & Sobral & 1 & 1 & 0,03 & - & - & - \\
\hline & Eugenia sp.08 & Sobral & 2 & 2 & 0,17 & - & - & - \\
\hline & Eugenia sp.09 & Sobral & 4 & 4 & 0,71 & - & - & - \\
\hline & Eugenia subavenia O.Berg & 49058 & - & - & - & 12 & 10 & 0,64 \\
\hline & Eugenia ternatifolia Cambess. & 49059 & 2 & 2 & 0,75 & 1 & 1 & 0,08 \\
\hline & Eugenia verticillata (Vell.) Angely & 49061 & 7 & 6 & 0,41 & 1 & 1 & 0,46 \\
\hline & Marlierea glazioviana Kiaersk. & 49063 & 18 & 17 & 1,92 & 2 & 2 & 0,61 \\
\hline & Marlierea racemosa (Vell.) Kiaersk. & 49066 & 9 & 9 & 5,24 & 1 & 1 & 0,32 \\
\hline & Marlierea sp.1 & Sobral & 4 & 4 & 0,39 & - & - & - \\
\hline & Marlierea sp.2 & Sobral & 1 & 1 & 0,02 & - & - & - \\
\hline & Marlierea sp.3 & Sobral & 1 & 1 & 0,03 & - & - & - \\
\hline & Marlierea sylvatica (O.Berg) Kiaersk. & 49064 & 5 & 5 & 1,61 & 6 & 6 & 5,84 \\
\hline & Marlierea tomentosa Cambess. & 49065 & 20 & 20 & 2,85 & 17 & 16 & 11,3 \\
\hline & Myrceugenia campestris (DC.) D.Legrand \& Kausel & 49067 & - & - & - & 2 & 2 & 0,06 \\
\hline & Myrceugenia myrcioides (Cambess.) O.Berg & 49068 & - & - & - & 6 & 6 & 0,38 \\
\hline & Myrcia aethusa (O.Berg) N.Silveira & 50372 & 5 & 5 & 0,84 & - & - & - \\
\hline & Myrcia guianensis (Aubl.) DC. & 50373 & 3 & 3 & 1,97 & - & - & - \\
\hline & Myrcia pubipetala Miq. & 50374 & 2 & 2 & 0,67 & - & - & - \\
\hline & Myrcia richardiana (O.Berg) Kiaersk. & 49069 & - & - & - & 2 & 2 & 0,14 \\
\hline & Myrcia sp.1(=Gomidesia blanchetiana O.Berg) & 49062 & - & - & - & 13 & 11 & 0,41 \\
\hline & Myrcia sp.5 & Sobral & 4 & 4 & 5,8 & & & \\
\hline & Myrcia spectabilis DC. & 49070 & 13 & 11 & 2,17 & 3 & 3 & 0,13 \\
\hline & Myrcia splendens (Sw.) DC. & 50376 & 2 & 2 & 0,41 & - & - & - \\
\hline & Myrciaria floribunda (H.West ex Willd.) O.Berg & 49071 & 3 & 3 & 0,37 & 18 & 16 & 6,46 \\
\hline & Neomitranthes glomerata (D.Legrand) D.Legrand & 49072 & 4 & 4 & 0,11 & 3 & 3 & 0,4 \\
\hline & Neomitranthes sp. & Sobral & 1 & 1 & 0,31 & - & - & - \\
\hline & Plinia edulis (Vell.) Sobral & 49073 & 5 & 5 & 2,04 & 1 & 1 & 0,82 \\
\hline & Plinia rivularis (Cambess.) Rotman & 50379 & 1 & 1 & 0,05 & - & - & - \\
\hline \multirow[t]{3}{*}{ Nyctaginaceae } & Guapira hirsuta (Choisy) Lundell & 49002 & 10 & 10 & 2,37 & 1 & 1 & 0,31 \\
\hline & Guapira nitida (Mart. ex J.A.Schmidt) Lundell & 49003 & 8 & 8 & 3,44 & 11 & 9 & 2,03 \\
\hline & Guapira opposita (Vell.) Reitz & 49004 & 16 & 15 & 8,35 & 28 & 24 & 20,2 \\
\hline
\end{tabular}


Tabela 1. Continuação...

\begin{tabular}{|c|c|c|c|c|c|c|c|c|}
\hline \multirow[t]{2}{*}{ Família } & \multirow[t]{2}{*}{ Espécies } & \multirow[t]{2}{*}{ IAC } & \multicolumn{3}{|c|}{ PLOT I } & \multicolumn{3}{|c|}{ PLOT G } \\
\hline & & & $\mathbf{N}$ & FrA & DoA & $\mathbf{N}$ & FrA & DoA \\
\hline & Guapira venosa (Choisy) Lundell & 50393 & 5 & 5 & 7,09 & - & - & - \\
\hline Ochnaceae & Ouratea parviflora (DC.) Baill. & 49005 & - & - & - & 15 & 15 & 0,94 \\
\hline \multirow[t]{2}{*}{ Olacaceae } & Heisteria silvianii Schwacke & 48958 & 4 & 4 & 1 & 2 & 2 & 0,43 \\
\hline & Tetrastylidium grandifolium (Baill.) Sleumer & 49006 & 2 & 2 & 0,11 & 4 & 4 & 1,91 \\
\hline Opiliaceae & Agronandra cf. excelsa Griseb. & 50397 & 1 & 1 & 0,1 & - & - & - \\
\hline Phyllanthaceae & Hieronyma alchorneoides Allemão & 50398 & 26 & 20 & 27,87 & 1 & 1 & 2,19 \\
\hline Phytolaccaceae & Phytolacca dioica $\mathrm{L}$. & 50400 & 1 & 1 & 0,09 & - & - & - \\
\hline Picramniaceae & Picramnia ciliata Mart. & 50401 & 1 & 1 & 0,03 & - & - & - \\
\hline Proteaceae & Roupala brasiliensis Klotzsch & 50402 & 9 & 7 & 2,46 & - & - & - \\
\hline Rosaceae & Prunus myrtifolia (L.) Urb. & 49007 & - & - & - & 1 & 1 & 0,14 \\
\hline \multirow[t]{24}{*}{ Rubiaceae } & Alseis floribunda Schott & 49029 & 2 & 2 & 0,14 & 8 & 8 & 1,38 \\
\hline & Amaioua intermedia Mart. & incluir & 2 & 2 & 1,36 & - & - & - \\
\hline & Bathysa australis (A.St.-Hil.) Benth. \& Hook.f. & 49031 & 1 & 1 & 0,18 & 25 & 21 & 5,69 \\
\hline & Bathysa mendoncaei K.Schum. & 49032 & 218 & 60 & 15,04 & 21 & 20 & 2,66 \\
\hline & Bathysa stipulata (Vell.) C.Presl & 49033 & - & - & - & 2 & 2 & 0,14 \\
\hline & Chomelia brasiliana A.Rich. & 50409 & 1 & 1 & 0,02 & - & - & - \\
\hline & Chomelia pedunculosa Benth. & 50410 & 4 & 4 & 0,2 & - & - & - \\
\hline & Coussarea accedens Müll.Arg. & 49034 & 9 & 8 & 0,66 & 60 & 46 & 3,99 \\
\hline & Coussarea meridionalis var. porophylla (Vell.) M.Gomes & 49035 & 81 & 53 & 6,55 & 39 & 31 & 2,83 \\
\hline & Faramea pachyantha Müll.Arg. & 49036 & 62 & 39 & 9,68 & 6 & 6 & 3,19 \\
\hline & Faramea picinguabae M.Gomes & 50411 & 1 & 1 & 0,02 & - & - & - \\
\hline & Guettarda viburnoides Cham. \& Schltdl. & 50413 & 2 & 2 & 0,74 & - & - & - \\
\hline & Ixora bracteolaris Müll.Arg. & 49037 & 2 & 2 & 0,13 & 1 & 1 & 0,04 \\
\hline & Posoqueria latifolia (Rudge) Roem. \& Schult. & 49038 & 10 & 9 & 3,68 & 1 & 1 & 0,09 \\
\hline & Psychotria birotula L.B.Sm. \& Downs & 49039 & - & - & - & 1 & 1 & 0,05 \\
\hline & Psychotria leitana C.M.Taylor & 50414 & 10 & 9 & 0,58 & - & - & - \\
\hline & Psychotria longipes Müll.Arg. & 50412 & 5 & 4 & 0,14 & - & - & - \\
\hline & Psychotria mapourioides DC. & 49030 & - & - & - & 1 & 1 & 0,05 \\
\hline & Psychotria nuda (Cham. \& Schltdl.) Wawra & 49040 & - & - & - & 20 & 18 & 0,64 \\
\hline & Psychotria patentinervia Müll.Arg. & 49041 & - & - & - & 1 & 1 & 0,02 \\
\hline & Psychotria pubigera Schltdl. & 50415 & 2 & 2 & 0,05 & - & - & - \\
\hline & Rudgea jasminoides (Cham.) Müll.Arg. & 49042 & 40 & 34 & 1,57 & 234 & 83 & 13,9 \\
\hline & Rudgea vellerea Müll.Arg. & 49043 & 13 & 12 & 1,28 & 13 & 13 & 1,31 \\
\hline & Rustia formosa (Cham. \& Schltdl.) Klotzsch & 50418 & 53 & 44 & 19,03 & - & - & - \\
\hline \multirow[t]{4}{*}{ Salicaceae } & Banara parviflora (Gray) Benth & 50431 & 1 & 1 & 0,11 & - & - & - \\
\hline & Casearia obliqua Spreng. & 50432 & 1 & 1 & 0,69 & - & - & - \\
\hline & Casearia sylvestris $\mathrm{Sw}$. & 50433 & 2 & 2 & 0,42 & 1 & 1 & 0,17 \\
\hline & Xylosma glaberrima Sleumer & 50434 & 3 & 3 & 0,47 & - & - & - \\
\hline \multirow[t]{6}{*}{ Sapindaceae } & Allophylus petiolulatus Radlk. & 49018 & 4 & 4 & 0,35 & 2 & 2 & 0,14 \\
\hline & Cupania furfuracea Radlk. & 49019 & 13 & 12 & 2,77 & 6 & 6 & 2,05 \\
\hline & Cupania oblongifolia Mart. & 49020 & 7 & 6 & 4,18 & 4 & 4 & 1,78 \\
\hline & Matayba elaeagnoides Radlk. & 49021 & 1 & 1 & 0,02 & - & - & - \\
\hline & Matayba juglandifolia (Cambess.) Radlk. & 50438 & 4 & 4 & 0,47 & 1 & 1 & 0,04 \\
\hline & Tripterodendron filicifolium Radlk. & 50439 & 2 & 2 & 0,04 & - & - & - \\
\hline \multirow[t]{5}{*}{ Sapotaceae } & Chrysophyllum flexuosum Mart. & 49026 & 21 & 17 & 1,52 & 27 & 21 & 2,97 \\
\hline & Chrysophyllum viride Mart. \& Eichler ex Miq. & 50441 & 1 & 1 & 0,42 & - & - & - \\
\hline & Ecclinusa ramiflora Mart. & 49027 & 39 & 32 & 18,45 & 5 & 5 & 7,76 \\
\hline & Manilkara subsericea (Mart.) Dubard & 50445 & 4 & 4 & 1,65 & - & - & - \\
\hline & $\begin{array}{l}\text { Micropholis crassipedicellata (Mart. \& Eichler ex Miq.) } \\
\text { Pierre }\end{array}$ & 49028 & 5 & 5 & 3,18 & 3 & 3 & 3,96 \\
\hline
\end{tabular}


Tabela 1. Continuação...

\begin{tabular}{|c|c|c|c|c|c|c|c|c|}
\hline \multirow[t]{2}{*}{ Família } & \multirow[t]{2}{*}{ Espécies } & \multirow[t]{2}{*}{ IAC } & \multicolumn{3}{|c|}{ PLOT I } & \multicolumn{3}{|c|}{ PLOT G } \\
\hline & & & $\mathbf{N}$ & FrA & DoA & $\mathbf{N}$ & FrA & DoA \\
\hline & Pouteria caimito (Ruiz \& Pav.) Radlk. & 49023 & 8 & 8 & 1,13 & 4 & 4 & 9,2 \\
\hline & Pouteria gardneri (Mart. \& Miq.) Baehni & 50448 & 1 & 1 & 0,04 & 2 & 2 & 0,25 \\
\hline & Pouteria psammophila (Mart.) Radlk. & 50449 & 8 & 6 & 0,92 & - & - & - \\
\hline & Pouteria venosa (Mart.) Baehni & 49024 & 1 & 1 & 1,88 & 5 & 5 & 3,28 \\
\hline & Pradosia lactescens (Vell.) Radlk. & 49025 & - & - & - & 1 & 1 & 1,8 \\
\hline & Sapotaceae sp.3 & 50466 & - & - & - & 1 & 1 & 0,28 \\
\hline Thymelaeaceae & Daphnopsis schwackeana Taub. & 49014 & 6 & 6 & 0,37 & 15 & 14 & 1,07 \\
\hline Urticaceae & Cecropia glaziovii Snethl. & 49016 & - & - & - & 6 & 6 & 2,2 \\
\hline & Coussapoa microcarpa (Schott) Rizzini & 49017 & 1 & 1 & 0,06 & 5 & 5 & 1,09 \\
\hline & Pourouma guianensis Aubl. & 49015 & 1 & 1 & 0,02 & 1 & 1 & 0,27 \\
\hline Vochysiaceae & Vochysia oppugnata (Vell.) Warm. & 50451 & 3 & 3 & 2,07 & - & - & - \\
\hline
\end{tabular}

Obtivemos 4,339 nats/indivíduos no índice de Shannon (H'), e $57,302 \mathrm{~m}^{2} \cdot \mathrm{ha}^{-1}$, para a área basal, aos $350 \mathrm{~m}$. Encontramos, nesta parcela, 57 árvores mortas, que juntas atingiram uma área basal de 1,4 $\mathrm{m}^{2} \cdot \mathrm{ha}^{-1}$. Aos $350 \mathrm{~m}$, as árvores vivas com DAP igual ou maior a $10 \mathrm{~cm}$ somaram 1.080 indivíduos (54\% do total de vivos) e 172 espécies ( $85 \%$ do total, tal como aos $190 \mathrm{~m}$ ).

Constatamos valores significativamente distintos em relação à densidade absoluta, entre as parcelas aos 190 e $350 \mathrm{~m}(\mathrm{p}<0,01$; $\mathrm{t}=7,10 ; \mathrm{gl}=198)$ e apenas quatro espécies se repetiram entre as dez mais abundantes em cada área: Coussarea meridionalis, Euterpe edulis, Rudgea jasminoides e Syagrus pseudococos.

Embora as espécies mais abundantes tenham se destacado entre as mais importantes e aquelas com maiores valores de cobertura, algumas espécies com poucos indivíduos ou não muito comuns, mas com árvores de grande porte, alcançaram elevados valores de imporância e cobertura, aos 190 m. Destacaram-se Sloanea guianensis, com 22 indivíduos, que lhe asseguraram a segunda posição no IVI e IVC, especialmente em função de sua dominância (primeira posição) de $7,51 \mathrm{~m}^{2}$.ha-1 $\left(0,34 \mathrm{~m}^{2}\right.$.ha-1 , em média, de dominância por indivíduo) e Vitex cymosa, com apenas três indivíduos (sendo um deles a maior árvore da parcela, com perímetro de 4,44 m), décima posição em IVI, quinta em IVC e terceira em dominância com 2,86 m².ha-1 $\left(0,95 \mathrm{~m}^{2}\right.$. $\mathrm{ha}^{-1}$ por indivíduo, maior média da parcela). Aos $350 \mathrm{~m}$, embora tenha sido observada a maior árvore (Pseudopiptadenia warmingii, com perímetro de 4,58 m), a importância relativa, por espécie, das grandes árvores mostrou-se menor, sendo que a segunda maior árvore da parcela ocupou apenas a oitava posição, considerando-se as duas áreas em conjunto. A espécie com maior média de dominância por indivíduo (Andira fraxinifolia, 0,99 $\mathrm{m}^{2} . \mathrm{ha}^{-1}$ ) foi representada por apenas uma árvore e ocupou apenas a quadragésima primeira posição em IVI, a vigésima nona em IVC e a décima sexta em dominância. Pseudopitadenia warmingii apresentou a segunda maior média de dominância $\left(0,84 \mathrm{~m}^{2} \cdot \mathrm{ha}^{-1}\right)$, tendo sido representada por apenas dois indivíduos, que ocuparam a vigésima segunda posição em IVI, a décima sexta em IVC e a nona em dominância. A maior dominância específica absoluta $\left(3,47 \mathrm{~m}^{2} \cdot \mathrm{ha}^{-1}\right.$, correspondendo a apenas, $0,13 \mathrm{~m}^{2} \cdot \mathrm{ha}^{-1}$ em média, de dominância por indivíduo) foi devida à Cryptocarya mandioccana, representada por 26 indivíduos, que ocuparam a sexta posição em IVI e a quarta em IVC.

Os valores de dominância que observamos não diferiram em relação às duas altitudes $(\mathrm{p}=0,101 ; \mathrm{t}=-1,65 ; \mathrm{gl}=198)$. Entretanto, o conjunto das dez espécies com as maiores dominâncias em cada parcela (aos 190 e $350 \mathrm{~m}$ ) resultou em 18 espécies distintas, sendo apenas duas em comum, entre as duas altitudes: Cryptocarya mandiocana (que além da primeira posição aos $350 \mathrm{~m}$, ocupou a segunda posição os $190 \mathrm{~m}$ ) e Slonea guianensis (que além da primeira posição aos $190 \mathrm{~m}$, ocupou a quarta posição aos $350 \mathrm{~m}$ ). $\mathrm{E}$, ao considerarmos o volume, observamos que os valores diferiam signficativamente entre as parcelas $(\mathrm{p}=0,02 ; \mathrm{t}=2,44 ; \mathrm{gl}=198)$, sendo maior aos $350 \mathrm{~m}\left(903,76 \mathrm{~m}^{3} \cdot \mathrm{ha}^{-1}\right)$ de altitude do que aos $190 \mathrm{~m}$ $\left(648,1 \mathrm{~m}^{3} \cdot \mathrm{ha}^{-1}\right)$.

As duas parcelas em estudo apresentaram valores significativamente distintos em relação à riqueza $(\mathrm{p}<0,01 ; \mathrm{t}=7,76$; $\mathrm{gl}=198$ ), sendo que a floresta aos $190 \mathrm{~m}$ somou 48 espécies exclusivas e a floresta aos $350 \mathrm{~m}$ somou 100 espécies exclusivas. No total, as espécies exclusivas em cada área representaram $59 \%$ das espécies observadas e, constatamos (Tabela 2) um elevado número de espécies consideradas ameaçadas (36 espécies, correspondendo a $14 \%$ do total de espécies encontradas). Entre elas, podemos destacar Macrotorus utriculatus (Figura 1) e Ocotea beyrichii que são consideradas "Criticamente em Perigo" (Brasil 2008) e Campomanesia laurifolia, Eugenia neoaustralis, Trichilia lepidota, Rudgea vellerea (Figura 1) e Virola bicuhyba que são consideradas "Em Perigo" (Brasil 2008). Ixora bracteolaris (Figura 1) foi recoletada apenas após cerca de 130 anos depois de sua descrição (Müller Argoviensis 1875), possibilitando as primeiras informações de sua fenologia publicados a partir de materiais por nós coletados, na área de estudo (Delprete 2008). Ainda, observamos três espécies inéditas: Miconia sp., uma nova Melastomataceae (R.Godemberg, informação pessoal); Maytenus sp.2 (Figura 1), uma nova Celastraceae (R. CarvalhoOkano, informação pessoal) e Calyptranthes ubatubana, uma nova Myrtaceae (Sobral et al., dados não publicados).

\section{Discussão}

Na região serrana do litoral norte paulista, a vegetação da Mata Atlântica comporta expressiva diversidade, sendo possível observar diferenças em sua estrutura, composição de espécies e riqueza entre áreas próximas entre si (menos que $1 \mathrm{~km}$ ), situadas em diferentes cotas altitudinais.

Nossos resultados indicam que a diversidade é maior próximo à região intermediária em altitude $(350 \mathrm{~m})$ nas montanhas relativamente baixas desta região do sudeste brasileiro (até cerca de $1.000 \mathrm{~m}$ ), tal como observado para montanhas de altitude semelhantes e igualmente frequentemente encobertas por nuvens, na Ásia (Proctor et al. 1988). Entretanto, Proctor et al. (1988) realizaram análises em um grandiente 
Tabela 2. Espécies ameaçadas de extinção no Estado de São Paulo, localizada no PLOT G (190 m) e PLOT I (350 m), Parque Estadual da Serra do Mar, Núcleo Picinguaba, Ubatuba/SP, Brasil.

Table 2. Species listed as endangered in the State of São Paulo, located in G PLOT (190 m) and PLOT I (350 m), Serra do Mar State Park, Núcleo Picinguaba, Ubatuba/SP, Brazil.

\begin{tabular}{|c|c|c|c|c|c|c|}
\hline Espécie & Família & $\begin{array}{c}\text { PLOT } \\
\text { I } \\
\end{array}$ & $\begin{array}{c}\text { PLOT } \\
\text { G }\end{array}$ & BR & IUCN & SMA 08 \\
\hline Astrocaryum aculeatissimum (Schott) Burret & Arecaceae & $\mathrm{x}$ & $\mathrm{x}$ & & LR & \\
\hline Euterpe edulis Mart. & Arecaceae & $\mathrm{x}$ & $\mathrm{x}$ & VU & & VU \\
\hline Syagrus pseudococos (Raddi) Glassman & Arecaceae & $\mathrm{x}$ & $\mathrm{x}$ & & LR & \\
\hline Protium kleinii Cuatrec. & Burseraceae & $\mathrm{x}$ & 0 & & & VU \\
\hline Terminalia januarensis DC. & Combretaceae & $\mathrm{x}$ & $\mathrm{x}$ & & VU & \\
\hline Erythroxylum pulchrum A.St.-Hil. & Erythroxylaceae & $\mathrm{x}$ & 0 & VU & & VU \\
\hline Copaifera langsdorffii Desf. & Fabaceae-Caesalpinoideae & $\mathrm{x}$ & $\mathrm{x}$ & & & QA \\
\hline Tachigali denudata (Vogel) Oliveira-Filho & Fabaceae-Caesalpinoideae & $\mathrm{x}$ & $\mathrm{x}$ & & LR & \\
\hline Myrocarpus frondosus Allemão & Fabaceae-Faboideae & 0 & $\mathrm{x}$ & & DD & QA \\
\hline Swartzia langsdorffii Raddi & Fabaceae-Faboideae & $\mathrm{x}$ & $\mathrm{x}$ & & & QA \\
\hline Inga grazielae (Vinha) T.D.Penn. & Fabaceae-Mimosoideae & 0 & $\mathrm{x}$ & & VU & \\
\hline Lacistema lucidum Schnizl. & Lacistemataceae & 0 & $\mathrm{x}$ & & DD & \\
\hline Ocotea beyrichii (Nees) Mez & Lauraceae & 0 & $\mathrm{x}$ & & & $\mathrm{CR}$ \\
\hline Ocotea odorifera (Vell.) Rohwer & Lauraceae & $\mathrm{x}$ & 0 & VU & & \\
\hline Ocotea tabacifolia (Meisn.) Rohwer & Lauraceae & 0 & $\mathrm{x}$ & & & VU \\
\hline Cariniana estrellensis (Raddi) Kuntze & Lecythidaceae & $\mathrm{x}$ & $\mathrm{x}$ & & & QA \\
\hline Cedrela odorata $\mathrm{L}$. & Meliaceae & 0 & $\mathrm{x}$ & & VU & QA \\
\hline Trichilia lepidota Mart. & Meliaceae & $\mathrm{x}$ & 0 & & EM & \\
\hline Macrotorus utriculatus Perkins & Monnimiaceae & $\mathrm{x}$ & 0 & VU & & $\mathrm{CR}$ \\
\hline Mollinedia argyrogyna Perkins & Monnimiaceae & $\mathrm{x}$ & 0 & & LR & \\
\hline Brosimum guianense (Aubl.) Huber & Moraceae & $\mathrm{x}$ & $\mathrm{x}$ & & & QA \\
\hline Ficus cf. hirsuta Schott & Moraceae & 0 & $\mathrm{x}$ & & LR & \\
\hline Virola bicuhyba (Schott ex Spreng.) Warb. & Myristicaceae & $\mathrm{x}$ & $\mathrm{x}$ & & EM & \\
\hline Campomanesia laurifolia Gardner & Myrtaceae & $\mathrm{x}$ & $\mathrm{x}$ & & EM & \\
\hline Eugenia brasiliensis Lam. & Myrtaceae & $\mathrm{x}$ & 0 & & & VU \\
\hline Eugenia neoaustralis Sobral & Myrtaceae & $\mathrm{x}$ & $\mathrm{x}$ & & EM & \\
\hline Eugenia prasina O.Berg & Myrtaceae & $\mathrm{x}$ & $\mathrm{x}$ & & VU & \\
\hline Myrceugenia campestris (DC.) D.Legrand \& Kausel & Myrtaceae & 0 & $\mathrm{x}$ & & VU & \\
\hline Myrceugenia myrcioides (Cambess.) O.Berg & Myrtaceae & 0 & $\mathrm{x}$ & & LR & \\
\hline Plinia edulis (Vell.) Sobral & Myrtaceae & $\mathrm{x}$ & $\mathrm{x}$ & & & VU \\
\hline Rudgea vellerea Müll.Arg. & Rubiaceae & $\mathrm{x}$ & $\mathrm{x}$ & EM & & \\
\hline Xylosma glaberrima Sleumer & Salicaceae & $\mathrm{x}$ & 0 & & DD & \\
\hline Chrysophyllum flexuosum Mart. & Sapotaceae & $\mathrm{x}$ & $\mathrm{x}$ & & LR & \\
\hline Chrysophyllum viride Mart. \& Eichler ex Miq. & Sapotaceae & $\mathrm{x}$ & 0 & & LR & \\
\hline Manilkara subsericea (Mart.) Dubard & Sapotaceae & $\mathrm{x}$ & 0 & & LR & \\
\hline Micropholis crassipedicellata (Mart. \& Eichler ex Miq.) Pierre & Sapotaceae & $\mathrm{x}$ & $\mathrm{x}$ & & LR & \\
\hline
\end{tabular}

maior, sendo que as áreas mais ricas foram aquelas em altitudes um pouco maiores (480-540 m). Aumentos de densidade nem sempre correspondem a aumentos de diversidade, sendo que o aumento da densidade com o aumento da altitude, observado por nós, está em acordo com os resultados geralmente encontrados, ao longo de gradientes altitudinais, nas florestas tropicais ao redor do mundo (Proctor et al. 1988, Rodrigues et al. 1989, Lieberman et al. 1996, Pendry \& Proctor 1997, Moreno et al. 2003).

Apesar das diferenças florísticas existentes entre as áreas por nós estudadas, apenas uma minoria de famílias e gêneros indicadores apresentou os padrões evidenciados para a Mata Atlântica em relação à elevação em altitude (Oliveira Filho \& Fontes 2000), ou seja, apenas para Meliaceae detectamos menos espécies para a altitude maior, enquanto para Erythroxylaceae, Myrsinaceae, Vochysiaceae e, especialmente, Monimiaceae observamos mais espécies para a altitude maior, tal como para Mollinedia, Rapanea ( Myrsine) e, especialmente, Miconia. Portanto, o padrão indicado (Oliveira Filho \& Fontes 2000) não é tão generalizado, podendo ser necessária uma maior amplitude de variação altitudinal para sua ocorrência ou a diversificação das famílias e gêneros indicadores ocorre entre regiões geográficas distintas. 

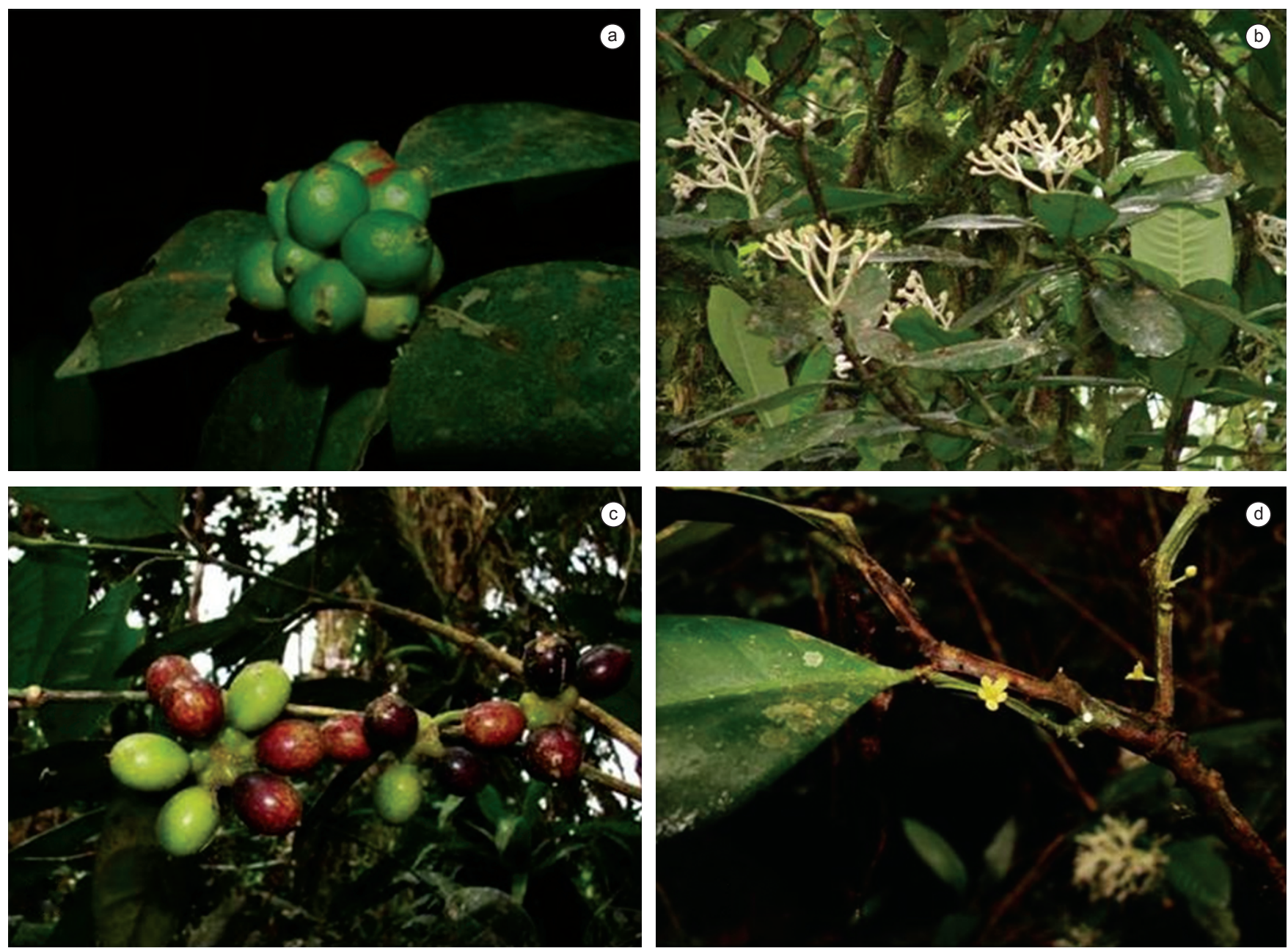

Figura 1. a) Ixora bracteolaris Müll.Arg. (Rubiaceae), b) Rudgea vellerea Müll.Arg. (Rubiaceae), c) Macrotorus utriculatus (Mart.) Perkins (Monimiaceae), d) Maytenus sp. 2 (Celastraceae) do Parque Estadual da Serra do Mar, Núcleo Picinguaba, Ubatuba/SP, Brasil.

Figure 1. a) Ixora bracteolaris Müll.Arg. (Rubiaceae), b) Rudgea vellerea Müll.Arg. (Rubiaceae), c) Macrotorus utriculatus (Mart.) Perkins (Monimiaceae), d) Maytenus sp.2 (Celastraceae) from the State Park Serra do Mar, Núcleo Picinguaba, Ubatuba/SP, Brazil.

Estando situada a mais de $20^{\circ}$ de latitude, surpreendemente a riqueza por nós observada aos $350 \mathrm{~m}$ foi a maior já observada até o momento (Tabela 3), na Mata Atlântica brasileira, considerando critérios semelhantes de inclusão (Silva \& Leitão Filho 1982, Leitão Filho et al. 1993, Melo \& Mantovani 1994, Melo et al. 1998, Sanches et al. 1999, Ivanauskas et al. 2001, Sztutman \& Rodrigues 2002, Moreno et al. 2003, Gomes et al. 2005). Embora, riquezas excessionalmente elevadas tenham sido encontradas em outros sítios, da Mata Atlântica, a metodologia diferiu da empregada por nós, tais como em Linhares - ES (Peixoto \& Gentry 1990), Morro Grande - SP e arredores (Bernacci et al. 2006; Catharino et al. 2006) e Serra do Conduru - BA (Martini et al. 2007), não possibilitando uma comparação direta. O número de espécies arbóreas com DAP igual ou maior que $10 \mathrm{~cm}$ que encontramos em cada uma das parcelas de 1 ha foi inferior a 200 espécies, tal como tem sido observado na Floresta Atlântica em São Paulo, sendo, contudo, notadamente aquele aos $350 \mathrm{~m}$ de altitude (172 espécies), superior à de vários sítios da Floresta Amazônica (Tabarelli \& Mantovani 1999).

A precipitação pluveométrica média anual em Ubatuba é umas das mais elevadas $(2.600 \mathrm{~mm})$, sendo superior a de inúmeras regiões em latitudes mais baixas, no domínio da Mata Atlântica, e muito próxima àquela encontrada em florestas com as maiores riquezas de epífitas, ervas, lianas, arbustos e pequenas árvores (2.980-7.470 mm), ao mesmo tempo em que o estoque de nitrogênio no solo, na área estudada (2-2,5 g. $\left.\mathrm{kg}^{-1}\right)$ se situa entre aqueles característicos de solos com níveis altos ou intermediários de fertilidade (1,3-8 g. $\left.\mathrm{kg}^{-1}\right)$, igualmente outro fator considerado importante para a determinação da riqueza de espécies vegetais (Tabarelli \& Mantovani 1999). Ou seja, as relativas fertilidade do solo e elevada precipitação pluveométrica ocorrentes nas nossas áreas de estudo podem ser fatores que auxiliam a explicar a grande riqueza observada, embora fosse esperada diversidade não muito elevada, em função da latitude em que se distribuem (Gentry 1988, Gvinish 1999, Tabarelli \& Mantovani 1999). Mas, embora se possa considerar a existência de tendências gerais de maior diversidade em locais de maior precipitação, existem exemplos que não se ajustam exatamente ao esperado, sendo que outras áreas da Mata Atlântica com diversidade excepcional (ex. Linhares - ES, Peixoto \& Gentry 1990; e Serra do Conduru - BA, Martini et al. 2007) têm precipitação média anual (1.403 e 1.800-2.200 mm, respectivamente) inferior à de Ubatuba. A frequente presença de nuvens e a consequente elevada humidade atmosférica (Gvinish 1999) é outro fator que pode estar associado à grande diversidade observada em Ubatuba. 
Tabela 3. Lista dos trabalhos analisados na comparação de riqueza sobre o domínio de Floresta Ombrófila Densa Atlântica no Estado de São Paulo.

Table 3. List of papers used in the comparison of species richness within the Atlantic Rain Forest Domain in São Paulo State.

\begin{tabular}{lccc}
\hline \multicolumn{1}{c}{ Referências } & Município /UF & N.sp & H' \\
\hline Presente estudo PLOT I & Ubatuba/SP & 203 & 4,33 \\
Ivanauskas et al. (2001) & Pariquera-Açu/SP & 183 & 4,13 \\
Melo et al. (1998) & Jureia-Itatins/SP & 178 & 4,19 \\
Presente estudo PLOT G & Ubatuba/SP & 151 & 3,95 \\
Leitão Filho (1993) & Cubatão/SP & 145 & 4,31 \\
Sztutman \& Rodrigues (2002) & Pariquera-Açu/SP & 144 & 4,06 \\
Silva e Leitão-Filho (1982) & Ubatuba/SP & 123 & 4,07 \\
Sanchez et al. (1999) & Ubatuba/SP & 120 & 4,07 \\
\hline
\end{tabular}

Diferenças na fertilidade do solo foram observadas entre os 0 e $1.000 \mathrm{~m}$, em Ubatuba, sendo que os solos entre 150 e $400 \mathrm{~m}$ foram aqueles que se mostraram, no geral, mais férteis (Martins 2010). Aos $350 \mathrm{~m}$, a amplitude de variação de altitude, com aclives e declives, é maior do que aos $190 \mathrm{~m}$, contribuindo para aumentar a heterogeineidade ambiental, que é outro fator que pode estar associado à diversidade (Oliveira \& Mori 1999, Webb \& Peart 2000), podendo ser a explicação para a maior diversidade observada aos $350 \mathrm{~m}$, em relação aos $190 \mathrm{~m}$. Em conjunto às variações de estrutura e composição, em função de variações altitudinais, a maior diversidade de espécies arbóreas corresponder àquela de altitudes intermediárias, é fato observado em diferentes montanhas de diferentes altitudes e continentes (Klein 1980, Proctor et al. 1988, Lieberman et al. 1996, Zhao et al. 2005, Grytnes \& Beaman 2006). A justificativa indicada para tal tipo de evento tem sido a ocorrência, no meio da encosta, de espécies de ambos extremos, ou seja, a ocorrência no meio da encosta de um bom número espécies que ocorrem na região do sopé e de espécies que ocorrem no cume. Portanto, a região do meio da encosta possuiria características intermediárias que seriam favoráveis à sobrevivência e desenvolvimento de um maior número de espécies do que aquele que pode ocorrer em cada um dos extremos. Esta condição mais favorável, na região mais próxima do meio da encosta, ou seja, aos $350 \mathrm{~m}$, pode ser evidenciada, além do número de espécies significativamente maior, pelo número significativamente maior de indivíduos, bem como pelo volume significativamente maior alcançado pela comunidade de árvores, em relação àquela dos $190 \mathrm{~m}$. A comparação, incluindo a parcela mais próxima, aos 375 m (parcela J - Rochelle et al. 2011), apontou que ambas são as áreas mais ricas em espécies, na floresta submontana (Joly et al. 2011), existindo 127 espécies em comum, entre as duas altitudes.

Considerando-se a parcela H (aos 208 m - Ramos et al. 2011), próxima àquela aos $190 \mathrm{~m}$, foram constatadas 101 espécies em comum, que é um valor próximo ao observado entre os 190 e $350 \mathrm{~m}$ (103 espécies), bem como entre os 350 e os 208 m (98 espécies). No geral, ocorreu um número maior de espécies em comum entre a área com maior riqueza $(350 \mathrm{~m})$, do que ao da área de menor diveresidade (aos $190 \mathrm{~m}$ ) em relação a todas as outras áreas nas diferentes cotas altitudinais, à exceção daquela aos $105 \mathrm{~m}$ (parcela F - Ramos et al. 2011), entre as quais o inverso foi observado e aquela aos $73 \mathrm{~m}$ (parcela $\mathrm{E}$ - Campos et al. 2011), entre as quais foi observado o mesmo número de espécies em comum (90 espécies), tanto em relação aos 190 como aos $350 \mathrm{~m}$. Respectivamente às áreas aos 56 (Campos et al. 2011), 46 (Assis et al. 2011), 1.020 e 1.025 (Pereira et al. 2011) e $10 \mathrm{~m}$ (Assis et al. 2011), foram observadas 93,
88, 64, 58 e 39 espécies em comum com a área aos 350 m, enquanto foram observadas $85,87,53,52$ e 28 espécies em comum com a área aos 190 m. Entre a área aos 105 m (parcela F - Ramos et al. 2011), ocorreram 65 espécies em comum com a área aos $190 \mathrm{~m}$ e apenas 55 espécies em comum com aquela aos $350 \mathrm{~m}$, sendo importante destacar que além da maior proximudade entre as áreas aos 105 e 190 m, do que entre as aos 105 e 350 m, a área aos 105 m é a mais antropizada entre aquelas estudadas no âmbito do projeto Biota Gradiente Funcional (FAPESP 03/12595-7 - Joly et al. 2008, 2011), sendo que segundo moradores antigos, a área foi explorada há cerca de 40 anos para a retirada seletiva de madeira da árvore urucurana (Hieronyma alchorneoides Allemão, Phyllanthaceae), entre outras. Portanto, o número menor de espécies em comum entre a área aos $350 \mathrm{~m}$ e aquela antropizada $(105 \mathrm{~m})$ e maior número de espécies em comum com as outras áreas são outras evidências das boas condições reinantes aos $350 \mathrm{~m}$.

Além da grande diversidade de espécies arbóreas encontrada em cada uma das altitudes (aos 190 e 350 m), muitas espécies foram observadas em apenas uma das altitudes, sendo, igualmente, observado um grande número de espécies ameaçadas de extinção. Considerando-se conjuntamente as duas parcelas estudadas (2 ha), a riqueza (252 espécies) foi maior do que em 10 ha, em Carlos Botelho (215 espécies - Souza et al. 2006). A grande ocorrência de espécies raras, pouco abundantes e pouco frequentes nesta região contribui para a grande diferença florística entre as áreas. Adicionalmente aos fatores ambientais, interações biológicas (polinização, dispersão, predação, doenças) podem ter papel relevante para determinar a diversidade em uma área, sendo que perdas em uma comunidade biótica (tal como entre os dispersores) tendem a levar ao empobrecimento de outras comunidades (tal como das árvores dispersas - Silva \& Tabarelli 2000). Grandes áreas protegidas, tal como é o caso do Parque Estadual da Serra do Mar, têm condições de garantir a sobrevivência de um grande conjunto de organismos, incluindo mamíferos de grande porte e espécies raras da fauna e flora (Conservation International do Brasil 2000), sendo que perdas de diversidade, tal como entre as árvores podem ser percebidas apenas depois de longa data (Metzger et al. 2009). A restauração e restabelecimento de florestas com grande diversidade embora sejam possíveis, envolvem altos custos, além de pré-condições adequadas, tal como fonte de sementes e diversidade na paisagem circundante (Rodrigues et al. 2009), ou seja, envolvem a necessidade da própria conservação de áreas com grande biodiversidade.

\section{Agradecimentos}

Este trabalho foi desenvolvido como parte do projeto BIOTA - FAPESP "Composição florística, estrutura e funcionamento da Floresta Ombrófila Densa dos Núcleos Picinguaba e Santa Virgínia do Parque Estadual da Serra do Mar" (FAPESP 03/12595-7), coordenado pelo terceiro autor (Joly) e pelo Dr. Luiz Antonio Martinelli (CENA/ USP). Agradecemos ao Instituto Florestal de São Paulo pelas autorizações de coleta concedidas, ao Sr. Oswaldo Alves dos Santos e a Fábio José Benedetti, pelo inestimável apoio nas atividades de campo, e aos taxonomistas Ângela B. Martins e Renato Goldenberg (Melastomataceae), Ariane Luna Peixoto (Monnimiaceae), Inês Cordeiro (Euphorbiaceceae), Fiorela Mazine e Marcos Sobral (Mytaceae), Marcelo A. Pinho-Ferreira e Sigrid L. Jung-Mendaçoli (Rubiaceae), João Batista Baitelo e Tiago D. M. Barbosa (Lauraceae), Edson Dias e Jorge Y. Tamashiro (Fabaceae), Julio A. Lombardi e Rita Carvalho-Okano (Celastraceae), João Semir (Asteraceae) e Marco A. Assis (Bignoniaceae), pelo auxílio com as nossas identificações. 


\section{Referências Bibliográficas}

AIBA, S. \& KITAYAMA, K. 1999. Structure, composition and species diversity in an altitude substrate matrix of rain forest tree communities on Mount Kinabalu, Borneo. Plant ecol. 140(2):139-157. http://dx.doi. org/10.1023/A:1009710618040

AIBA, S., KITAYAMA, K. \& TAKYU, M. 2004. Habitat associations with topography and canopy structure of tree species in a montane forest on Mount Kinabalu, Borneo. Plant ecol. 174(1):147-161. http://dx.doi. org/10.1023/B:VEGE.0000046059.92806.49

ANGIOSPERM PHYLOGENY GROUP - APG II. 2003. An update of the Angiosperm Phylogeny Group classification for the orders and families of flowering plants: APG II. Bot. j. Linn. Soc. 141(4):399-436. http:// dx.doi.org/10.1046/j.1095-8339.2003.t01-1-00158.x

ASSIS, M.A 1999. Florística e Caracterização das Comunidades Vegetais da Planície Costeira de Picinguaba, Ubatuba - SP. Tese de doutorado, Universidade Estadual de Campinas, Campinas.

ASSIS, M.A., PRATA, E.M.B; PEDRONI, F., SANCHEZ, M., EISENLOHR, P.V., MARTINS, F.R., SANTOS, F.A.M., TAMASHIRO, J.Y., ALVES, L.F., VIEIRA, S.A., PICCOLO, M.C., MARTINS, S.C;; CAMARGO, P.B., CARMO, J.B., SIMÕES, E., MARTINELLI, L.A. \& JOLY, C.A. 2011. Florestas de Restinga e de Terras Baixas na Planície Costeira do sudeste do Brasil: vegetação e heterogeneidade ambiental. Biota Neotrop. 11(2): http://www.biotaneotropica.org.br/v11n2/pt/ abstract?article+bn02111022011

AYRES, M., AYRES JUNIOR, M., AYRES, D.L. \& SANTOS, A.S. 2000. BioEstat 2.0: aplicações estatísticas nas áreas de ciências biológicas e médicas. Sociedade Civil Manirauá/CNPq, Belém.

BARBOSA, J.P.M. 2006. Utilização de método de interpolação para análise e espacialização de dados climáticos: o SIG como ferramenta. Cam. Geog. 9 (17):85-96.

BERNACCI, L.C., FRANCO, G.A.D.C., ÁRBOCZ, G.F., CATHARINO, E.L.M., DURIGAN, G. \& METZGER, J.P. 2006. O efeito da fragmentação florestal na composição e riqueza de árvores na região da Reserva Morro Grande (Planalto de Ibiúna, SP). Rev. Inst. Florest. 18(1):121-166.

BIODIVERSITAS. 2008. Lista oficial de espécies ameaçadas de extinção no Brasil. Disponível em: http://www.biodiversitas.org.br/florabr/grupo3fim. asp. (último acesso em 28/04/2011).

BRASIL. 2008. Secretaria do Meio Ambiente - SMA. Resolução SMA 08: Fixa a orientação para o reflorestamento heterogêneo de áreas degradadas e dá providências correlatas. Diário Oficial do Estado de São Paulo, Brasília, DF, 31 jan. 2008

CAMPOS, M.C.R., TAMASHIRO, J.Y., ASSIS, M.A. \& JOLY, C.A 2011. Florística e fitossociologia do componente arbóreo da transição Floresta Ombrófila Densa das Terras Baixas - Floresta Ombrófila Densa Submontana do Núcleo Picinguaba/PESM, Ubatuba, sudeste do Brasil. Biota Neotrop. 11(2): http://www.biotaneotropica.org.br/v11n2/pt/abstr act?inventory+bn02311022011

CARVALHO, D.A., OLIVEIRA FILHO, A.T., VANDEN BERG, E., FONTES, M.A.L., VILELA, E.A., MARQUES, J.J.G.S.M. \& CARVALHO, W.A.C. 2005. Variações florísticas e estruturais do componente arbóreo de uma Floresta Ombrófila Alto-Montana às margens do rio Grande, Bocaina de Minas, MG, Brasil. Acta Bot. Bras. 19(1):91-109. http://dx.doi. org/10.1590/S0102-33062005000100010

CATHARINO, E.L.M., BERNACCI, L.C., FRANCO, G.A.D.C., DURIGAN, G. \& METZGER, J.P. 2006. Aspectos da composição e diversidade do componente arbóreo das florestas da Reserva Florestal do Morro Grande, Cotia, SP. Biota Neotrop. 6(2): http://www.biotaneotropica.org.br/v6n2/ pt/fullpaper?bn00306022006+pt (último acesso 28/04/2011).

CESAR, O. \& MONTEIRO, R. 1995. Florística e fitossociologia de uma floresta sobre a restinga em Picinguaba (Parque Estadual da Serra do Mar) município de Ubatuba, SP. Naturalia 20(1):21-35

CIELO FILHO, R., GNERI, M.A. \& MARTINS, F.R. 2007. Position on slope, disturbance, and tree species coexistence in a Seasonal Semideciduous Forest in SE Brazil. Plant ecol. 190(2):189-203. http://dx.doi.org/10.1007/ s11258-006-9200-x
CONSERVATION INTERNATIONAL DO BRASIL, FUNDAÇÃO SOS MATA ATLÂNTICA, FUNDAÇÃO BIODIVERSITAS, INSTITUTO DE PESQUISAS ECOLÓGICAS, SECRETARIA DO MEIO AMBIENTE DO ESTADO DE SÃO PAULO, INSTITUTO ESTADUAL DE FLORESTAS-MG. 2000. Avaliação e ações prioritárias para a conservação da biodiversidade da Mata Atlântica e Campos Sulinos. MMA/SBF, Brasília.

DELPRETE, P.G. 2008. Ixora. In Flora Fanerogâmica do Estado de São Paulo (M.G.L. Wanderley, G.J. Shepherd, T.S. Melhem \& A.M. Giulietti, coords.). Instituto de Botânica, São Paulo, v.5, p.354-358.

FURLAN, A., MONTEIRO R., CESAR, O. \& TIMONI J.L. 1990. Estudos Florísticos das Matas de Restinga de Picinguaba, SP. Publ. ACIESP 71(3):220-227.

GARCIA, J.P.M. 1995. Análise geomorfológica e distribuição espacial da vegetação na planície litorânea de Picinguaba (Ubatuba - SP). Dissertação de mestrado, Universidade de São Paulo, São Paulo.

GENTRY, A.H. 1988. Changes in plant community diversity and floristic composition on environmental and geographical gradients. Ann. Missouri Bot. Gar. 75(1):1-34. http://dx.doi.org/10.2307/2399464

GOMES, E.P.C., FISCH, S.T.V. \& MANTOVANI, W. 2005. Estrutura e composição do componente arbóreo na Reserva Ecológica do Trabiju, Pindamonhangaba, SP, Brasil. Acta Bot. Bras. 19(3):451-464. http://dx.doi.org/10.1590/S0102-33062005000300005

GRYTNES, J.A. \& BEAMAN, J.H. 2006. Elevational species richness patterns for vascular plants on Mount Kinabalu, Borneo. J. Biogeogr. 33(10):1838-1849. http://dx.doi.org/10.1111/j.1365-2699.2006.01554.x

GUEDES-BRUNI, R.R. \& LIMA, H.C. 1997. Mountain ranges of Rio de Janeiro, South-eastern Brazil. In Centres of plant diversity: a guide and strategy for their conservation (S.D. Davis, V.H. Heywood, O. Herrera-MacBryde, J. Villa-Lobos \& A.C. Hamilton, eds.). WWF/IUCN, Cambridge, v.3, p.376-380.

GVINISH, T.J. 1999. On the causes of gradients in tropical tree diversity. J. Ecol. 87(2):193-210. http://dx.doi.org/10.1046/j.1365-2745.1999.00333.x

INSTITUTO FLORESTAL. Parque Estadual da Serra do Mar: Núcleo Picinguaba - floresta e mar. http://www.iflorestsp.br/picinguaba.htm (último acesso em 28/04/2011).

INTERNATIONAL UNION FOR CONSERVATION OF NATURE - IUCN 2006. 2006 IUCN Red List of Threatened Species. http://www.iucnredlist. org (último acesso em 30/11/2009).

IVANAUSKAS, N.M., MONTEIRO, R. \& RODRIGUES, R.R. 2000. Similaridade florística entre áreas de Floresta Atlântica no Estado de São Paulo. Braz. J. Ecol. 1/2(1):71-81.

IVANAUSKAS, N.M., MONTEIRO, R. \& RODRIGUES, R.R. 2001. Levantamento florístico de um trecho de Floresta Atlântica em PariqueraAçu, SP. Naturalia 26(1):97-129.

JOLY, C.A., AIDAR, M.P.M., KLINK, C.A., McGRAPH, D.G., MOREIRA, A.G., MOUTINHO, P., NEPSTAD, D.C., OLIVEIRA, A.A., POTT, A. \& SAMPAIO, E.V.S.B. 1999. Evolution of the Brazilian phytogeography classification systems: implications for biodiversity conservation. Cienc. Cult. 51(5/6):331-348.

JOLY, C.A., ASSIS, M.A., BERNACCI, L.C., TAMASHIRO, J.Y., CAMPOS, M.C.R., GOMES, J.A.M.A., SANCHEZ, M., SANTOS, F.A.M., PEDRONI, F., PEREIRA, L.S., PADGURSCHI, M.C., PRATA, E.M.B., RAMOS, E., TORRES, R.B., ROCHELLE, A.L.C., MARTINS, F.R, ALVES, L.F., VIEIRA, S.A., MARTINELLI, L.A., CAMARGO, P.B., SIMÕES, E., VILLANI, J.P. \& BELINELLO, R. 2011. Florística e fitossociologia do componente arbóreo da Mata Atlântica ao longo do gradiente altitudinal dos Núcleos Picinguaba e Santa Virgínia/PESM, do sudeste do Brasil. Biota Neotrop. 11(2): no prelo. 
JOLY, C.A., MARTINELLI, L.A., ALVES, L.F., VIEIRA, S.A., TAMASHIRO, J.Y., AIDAR, M.P.M., CAMARGO, P.B., ASSIS, M.A., BERNACCI, L.C. \& DURIGAN, G. 2008. As Parcelas Permanentes do Projeto Temático Biota Gradiente Funcional: Composição Florística, Estrutura e Funcionamento da Floresta Ombrófila Densa dos Núcleos Picinguaba e Santa Virgínia do Parque Estadual da Serra do Mar, Estado de São Paulo, Brasil. In Experiências de monitoramento no Bioma Mata Atlântica com uso de parcelas permanentes (C.R. Sanquetta, org.) RedeMAP - Rede de Parcelas Permanentes dos Biomas Mata Atlântica e Pampa/Funpar, Curitiba, p.109-148.

KLEIN, R.M.1980. Ecologia da flora e vegetação do Vale do Itajaí. Sellowia 32(32): 164-369.

KÖPPEN, W. 1948. Climatologia. Fondo de Cultura Económica, Cidade do México.

LEITÃO FILHO, H.F. 1987. Considerações sobre s florística de florestas tropicais e sub-tropicais do Brasil. Inst. Pesqui. Estud. Florest. 35(1):4146.

LEITÃO FILHO, H.F., PAGANO, S.N., CESAR, O., TIMONI, J.L. \& RUEDA, J.J. 1993. Ecologia da Mata Atlântica em Cubatão. Universidade Estadual Paulista/Universidade Estadual de Campinas, Campinas.

LEITE, P. \& KLEIN, R.M. 1990. Vegetação. In Geografia do Brasil: região Sul. IBGE, Rio de Janeiro, v.2, p.113-150.

LIEBERMAN, M., LIEBERMAN, D., HARTSHORN, G. \& PERALTA, R. 1985. Small-scale altitudinal variation in lowland wet tropical forest vegetation. J. Ecol. 73(2):505-516. http://dx.doi.org/10.2307/2260490

LIEBERMAN, D., LIEBERMAN, M., PERALTA, R. \& HARTSHORN, G.S. 1996. Tropical forest structure and composition on a large-scale altitudinal gradient in Costa Rica. J. Ecol. 84(2):137-152. http://dx.doi. org/10.2307/2261350

MAGURRAN, A.E. 1988. Ecological diversity and its measurement. Princeton University, New Jersey.

MARTINI, A.M.Z., FIASCHI, P., AMORIM, A.M. \& PAIXÃO, J.L. 2007. A hot-point within a hot-spot: a high diversity site in Brazil's Atlantic Forest. Biodivers. Conserv. 16(11):3111-3128. http://dx.doi.org/10.1007/ s10531-007-9166-6

MARTINS, S.C. 2010. Caracterização dos solos e serapilheira ao longo do gradiente altitudinal da Mata Atlântica, Estado de São Paulo. Tese de doutorado, Universidade de São Paulo, Piracicaba.

MARTINS, V.S., SILVA, N.R.S., SOUZA, A.L. \& MEIRA NETO, J.A.A. 2003. Distribuição de espécies arbóreas em um gradiente topográfico de Floresta Estacional Semidecidual em Viçosa, MG. Sci. For. 64(1):172181.

MEIRELES, L.D., SHEPHERD, G.J. \& KINOSHITA, L.S. 2008. Variações na composição florística e na estrutura fitossociológica de uma floresta ombrófila densa alto-montana na Serra da Mantiqueira, Monte Verde, MG. Rev. Bras. Bot. 31(4):559-574. http://dx.doi.org/10.1590/S010084042008000400003

MELO, M.M.R.F. \& MANTOVANI, W. 1994. Composição florística e estrutura de trecho de Mata Atlântica de encosta, na Ilha do Cardoso (Cananéia, SP, Brasil). Bol. Inst. Bot. 9(1):107-158.

MELO, M.M.R.F., OLIVEIRA, R.J., ROSSI, L., MAMEDE, M.C.H. \& CORDEIRO, I. 1998. Fitossociologia de trecho de Mata Atlântica na Planície do Rio Verde, Estação Ecológica de Juréia, Itatins, SP, Brasil. Publ. ACIESP 104(2): 49-56.

METZGER, J.P., MARTENSEN, A.C., DIXO, M., BERNACCI, L.C., RIBEIRO, M.C. \& TEIXEIRA, A.M.G. 2009. Time-lag in biological responses to landscape changes in a highly dynamic Atlantic forest region. Biol. Conserv. 142(6):1166-1177. http://dx.doi.org/10.1016/j. biocon.2009.01.033

MONTEIRO, E.A. \& FISCH, S.T.V. 2005. Estrutura e padrão espacial das populações de Bactris setosa Mart. e B. hatschbachii Noblick ex A.Hend (Arecaceae) em um gradiente altitudinal, Ubatuba (SP). Biota Neotrop. 5(2): http://www.biotaneotropica.org.br/v5n2/pt/ fullpaper?bn00505022005+pt (último acesso em 28/04/2011)

MORELLATO, L.P.C. 2000. The Brazilian Atlantic Forest. Biotropica 32(4b):786-792. http://dx.doi.org/10.1111/j.1744-7429.2000.tb00618.x
MORENO, M.R., NASCIMENTO, M.T. \& KURTZ, B.C. 2003. Estrutura e composição florística do estrato arbóreo em duas zonas altitudinais na mata atlântica de encosta da região do Imbé. RJ. Acta Bot. Bras. 17(3):371-386.

MORI, S.A., BOOM, B.M. \& PRANCE, G.T. 1981. Distribution patterns and conservation of Eastern Brazilian Coastal Forest tree species. Brittonia 33(2):233-245. http://dx.doi.org/10.2307/2806330

MUELLER-DOMBOIS, D. \& ELLENBERG, H. 1974. Aims and methods of vegetation ecology. John Wiley \& Sons, New York.

MÜLLER ARGOVIENSIS, J. 1875. Rubiaceae brasilienses novae. Flora 58(29):449-464.

ODLAND, A. \& BIRKS, H.J.B. 1999. The altitudinal gradient of vascular plant richness in Aurland, western Norway. Ecography 22(5):548-566.

OLIVEIRA, A.A. \& MORI, S.A. 1999. A central Amazonian terra firme Forest. I: high tree species richness on poor soils. Biodivers. Conserve. 8(9):1219-1244. http://dx.doi.org/10.1023/A:1008908615271

OLIVEIRA FILHO, A.T., CURI, N., VILELA, E.A. \& CARVALHO, D.A. 1998. Effects of canopy gaps, topography, and soils on the distribution of woody species in a Central Brazilian deciduous dry forest. Biotropica 30(3):362-375. http://dx.doi.org/10.1111/j.1744-7429.1998.tb00071.x

OLIVEIRA FILHO, A.T. \& FONTES, M.A.L. 2000. Patterns of floristic differentiation among Atlantic Forests in Southeastern Brazil and the influence of climate. Biotropica 32(4b):793-810. http://dx.doi. org/10.1111/j.1744-7429.2000.tb00619.x

OLIVEIRAFILHO, A.T., VILELA, E.A.,CARVALHO,D.A.\& GAVILANES, M.L. 1994. Effects of soil and topography on the distribution of tree species in a tropical riverine forest of southeastern Brazil. J. Trop. Ecol. 10(4):483-508. http://dx.doi.org/10.1017/S0266467400008178

PEIXOTO, A.L. \& GENTRY, A. 1990. Diversidade e composição florística da mata de tabuleiro na Reserva Florestal de Linhares (Espírito Santo. Brasil). Rev. Bras. Bot. 13(1):19-25.

PENDRY, C.A. \& PROCTOR, J. 1997. Altitudinal zonation of rain forest on Bukit Belalong, Brunei: soils, forest structure and floristic. J.Trop. Ecol. 13(2):221-241. http://dx.doi.org/10.1017/S0266467400010427

PEREIRA, L.S., PADGURSCHI, M.C.G., TAMASHIRO, J.Y. \& JOLY, C.A. 2011. Composição florística e estrutura fitossociológica em dois trechos da floresta ombrófila densa montana do Parque Estadual da Serra do Mar (Núcleo Santa Virgínia, São Luiz do Paraitinga - SP). Biota Neotrop. 11(2): no prelo.

PROCTOR, J., LEE, Y.F., LANGLEY, A.M., MUNRO, W.R.C. \& NELSON, T. 1988. Ecological studies on Gunung Silam, a small ultrabasic mountain in Sabah, Malaysia. J. ecol. 76(2):320-340. http://dx.doi. org/10.2307/2260596

RAMOS, E; TORRES, R.B., VEIGA, R.F.A. \& JOLY, C.A. 2011. Estudo do componente arbóreo de trechos da Floresta Ombrófila Densa Submontana em Ubatuba (SP). Biota Neotrop. 11(2): http://www.biotaneotropica.org. br/v11n2/pt/abstract?inventory+bn02411022011

ROCHELle, A.L.C., CIELO FILHO, R. \& MARTINS, F.R. 2011. Fitossociologia da comunidade arbórea de um trecho de Floresta Ombrófila Densa Atlântica no Parque Estadual da Serra do Mar, em Ubatuba, SP. Biota Neotrop. 11(2): http://www.biotaneotropica.org.br/ v11n2/pt/abstract?inventory+bn02711022011

RODRIGUES, R.R., LIMA, R.A., GANDOLFI, S. \& NAVE, A.G. 2009. On the restoration of high diversity forests: 30 years of experience in the Brazilian Atlantic Forest. Biol. Conserv. 142(6):1242-1251. http://dx.doi. org/10.1016/j.biocon.2008.12.008

RODRIGUES, R.R., MORELLATO, L.P.C., JOLY, C.A. \& LEITÃO FILHO, H.F. 1989. Estudo florístico e fitossociológico em um gradiente altitudinal de mata estacional mesófila semidecídua, na Serra do Japi, Jundiaí, SP. Rev. Brasil. Bot. 12(1/2):71-89.

SALIS, S.M., SHEPHERD, G.J. \& JOLY, C.A. 1995. Floristic comparison of mesophytic semideciduous forest of the interior of the state of São Paulo, Southeast Brazil. Vegetatio 119(2):155-164. http://dx.doi.org/10.1007/ BF00045595 
SANCHEZ, M. 2001. Composicão Florística e estrutura da comunidade arbórea num gradiente altitudinal da Mata Atlântica. Tese de doutorado, Universidade Estadual de Campinas, Campinas.

SANCHEZ, M., PEDRONI. F., LEITÃO FILHO, H.F. \& CÉSAR, O. 1999. Composição florística de um trecho de floresta ripária na Mata Atlântica em Picinguaba. Ubatuba. SP. Rev. Bras. Bot. 22(1):31-42. http://dx.doi. org/10.1590/S0100-84041999000100006

SCUDELLER, V.S., MARTINS, F.R. \& SHEPHERD, G.J. 2001. Distribution and abundance of arboreal species in the atlantic ombrophilous dense forest in Southeastern Brazil. Plant Ecol. 152(2):185-199. http://dx.doi. org/10.1023/A:1011494228661

SILVA, A.F. \& LEITÃO FILHO, H.F. 1982. Composição florística e estrutura de um trecho da mata atlântica de encosta no Município de Ubatuba - SP. Rev. Bras. Bot. 5(1/2):43-52.

SILVA, J.M.C. \& TABARELLI, M. 2000. Tree species impoverishment and the future flora of the Atlantic forest of northeast Brazil. Nature 404(6773):72-74. http://dx.doi.org/10.1038/35003563

SHEPHERD, G.J. 1995. FITOPAC 1: manual do usuário. Departamento de Botânica, Instituto de Biologia - UNICAMP, Campinas.

SOUZA, V.C., DUARTE, A.R., COUTINHO, A.P.S., SAMPAIO, D., BREIER, T.B., UDULUTSCH, R.G., RANDO, J.G., FERREIRA, M.A.P., OLIVEIRA, A.A., SEMIR, J., DURIGAN, G. \& RODRIGUES, R.R. 2006. Flora In Rodrigues, R.R. (coord.) $4^{\circ}$ Relatório Temático do Projeto Parcelas Permanentes. Laboratório de Ecologia e Restauração Floresta, Piracicaba. http://www.lerf.esalq.usp.br/old/parcelas/relatorio2005/ parteIII.pdf (último acesso em 28/04/2011).

SRUATEK, M. \& KOLBEK, J. 1994. Vegetation structure along the altitudinal gradient at the treeline of Mount Paektu, North Korea. Ecol. Res. 9(3):303310. http://dx.doi.org/10.1007/BF02348416

SZTUTMAN, M. \& RODRIGUES, R.R. 2002. O mosaico vegetacional numa área de floresta contínua da planície litorânea, Parque Estadual da Campina do Encantado, Pariquera-Açu, SP. Rev. Bras. Bot. 25(2):161176. http://dx.doi.org/10.1590/S0100-84042002000200005

TABARELLI, M. \& MANTOVANI, W. 1999. A riqueza de espécies arbóreas na floresta atlântica de encosta no Estado de São Paulo (Brasil). Rev. Bras. Bot. 22(2):217-223.

TAKYU, M., AIBA, S. \& KITAYAMA, K. 2002a. Effects of topography on tropical lower montane forests under different geological conditions on Mount Kinabalu, Borneo. Plant Ecol. 159(1):35-49. http://dx.doi. org/10.1023/A:1015512400074

TAKYU, M., AIBA, S. \& KITAYAMA, K. 2002b. Beta-diversity and changes in population structure along topographical gradients on different geological substrates in tropical montane forests on Mount Kinabalu, Borneo. Sabah Parks Nat. J. 5(1):165-218.
THOMAS, L.D. 1998. Floração e frutificação de algumas espécies de Mata Atlântica. Publ. ACIESP 104(2):135-141.

TORRES, R.B., MARTINS, F.R. \& KINOSHITA, L.S. 1997. Climate, soil and tree flora relationships in forests in the state of São Paulo, Southestern Brazil. Rev. Bras. Bot. 20(1):41-49.

VELOSO, P.H., RANGEL FILHO, A.L.R. \& LIMA, J.C.A. 1991. Classificação da vegetação brasileira, adaptada a um sistema universal. IBGE, Rio de Janeiro.

YAMAKURA, T., KANZAKI, M., ITOH, A., OHKUBO, T., OGINO, K., CHAI, E.O.K., LEE, H.S. \& ASHTON, P.S. 1995. Topography of a largescale research plot established within a tropical rain forest at Lambir, Sarawak. Tropics 5(1/2):41-56. http://dx.doi.org/10.3759/tropics.5.41

TROPICOS. http://www.tropicos.org/Home.aspx (último acesso em 28/04/2011).

WEBB, C.O. \& PEART, D.R. 2000. Habitat associations of trees and seedlings in a Bornean rain forest. J. Ecol. 88(3):464-478. http://dx.doi. org/10.1046/j.1365-2745.2000.00462.x

WORLD CHECKLIST OF SELECTED PLANT FAMILIES. http://apps.kew. org/wcsp/qsearch.do (último acesso em 28/04/2011).

WANDERLEY, M.G.L., SHEPHERD, G.J. \& GIULIETTI, A.M. (coords.). 2002. Flora Fanerogâmica do Estado de São Paulo. FAPESP/HUCITEC, São Paulo, v.2.

WANDERLEY, M.G.L., SHEPHERD, G.J., GIULIETTI, A.M. \& MELHEM. T.S. (coords.) 2003. Flora Fanerogâmica do Estado de São Paulo. RiMA, São Paulo, v.3.

WANDERLEY, M.G.L., SHEPHERD, G.J., GIULIETTI, A.M. \& MELHEM. T.S. (coords.) 2005. Flora Fanerogâmica do Estado de São Paulo. RiMA, São Paulo, v.4.

WANDERLEY, M.G.L., SHEPHERD. G.J., MELHEM. T.S. \& GIULIETTI. A.M. (coords.) 2007. Flora Fanerogâmica do Estado de São Paulo. Instituto de Botânica, São Paulo, v.5.

WANDERLEY, M.G.L., SHEPHERD. G.J., MELHEM. T.S., GIULIETTI. A.M. \& Martins, S.E. (coords.) 2009. Flora Fanerogâmica do Estado de São Paulo. Instituto de Botânica/FAPESP, São Paulo, v.6.

WHITTAKER, R.J., WILLIS, K.J. \& FIELD, R. 2001. Scale and species richness: towards a general, hierarchical theory of species diversity. J. Biogeogr. 28(4):453-470. http://dx.doi.org/10.1046/j.13652699.2001.00563.x

ZAR, J.H. 1999. Bioestatistical Analysis. $4^{\text {nd }}$ ed. Prentice-Hall Inc., New Jersey.

ZHAO, C.-M., CHEN, W.-L., TIAN, Z.-Q. \& XIE, Z.-Q. 2005. Altitudinal pattern of plant species diversity in Shennongjia Mountains, Central China. J. Integr. Plant Biol. 47(12):1431-1449. http://dx.doi.org/10.1111/ j.1744-7909.2005.00164.x 